\title{
Architecture and Healing
}

Culturally Appropriate Design in the Canadian Arctic

\section{Morgan Ip}

\section{A thesis submitted to the Faculty of Graduate Studies and Research \\ in partial fulfillment of the requirements for the degree of \\ Master of Architecture}

\author{
Azrieli School of Architecture, Carleton University \\ Ottawa, Canada \\ Morgan Ip (C) 2009
}




\section{Library and Archives Canada}

Published Heritage

Branch

395 Wellington Street Ottawa ON K1A 0N4 Canada
Bibliothèque et

Archives Canada

Direction du

Patrimoine de l'édition

395 , rue Wellington

Ottawa ON K1A 0N4

Canada
Your file Votre référence
ISBN: $978-0-494-60278-2$
Our file Notre référence
ISBN: $978-0-494-60278-2$
NOTICE:

The author has granted a nonexclusive license allowing Library and Archives Canada to reproduce, publish, archive, preserve, conserve, communicate to the public by telecommunication or on the Internet, loan, distribute and sell theses worldwide, for commercial or noncommercial purposes, in microform, paper, electronic and/or any other formats.

The author retains copyright ownership and moral rights in this thesis. Neither the thesis nor substantial extracts from it may be printed or otherwise reproduced without the author's permission.
AVIS:

L'auteur a accordé une licence non exclusive permettant à la Bibliothèque et Archives Canada de reproduire, publier, archiver, sauvegarder, conserver, transmettre au public par télécommunication ou par l'internet, prêter, distribuer et vendre des thèses partout dans le monde, à des fins commerciales ou autres, sur support microforme, papier, électronique et/ou autres formats.

L'auteur conserve la propriété du droit d'auteur et des droits moraux qui protège cette thèse. $\mathrm{Ni}$ la thèse ni des extraits substantiels de celle-ci ne doivent être imprimés ou autrement reproduits sans son autorisation.
In compliance with the Canadian Privacy Act some supporting forms may have been removed from this thesis.

While these forms may be included in the document page count, their removal does not represent any loss of content from the thesis.
Conformément à la loi canadienne sur la protection de la vie privée, quelques formulaires secondaires ont été enlevés de cette thèse.

Bien que ces formulaires aient inclus dans la pagination, il n'y aura aucun contenu manquant.

\section{Canadä}




\begin{abstract}
Elders in the remote hamlet of Kinngait (Cape Dorset) expressed a strong desire to have a cultural healing centre designed and built for their community. This building program was taken as an opportunity to discover what could be an appropriate architecture that responded to the arctic climate, with results relating back to housing. The notion of healing was taken as a powerful metaphor for architecture that proved itself literally in the design and dialogue within the community. Appropriateness meant to consider people and their social and cultural values, and using architecture as an interface between both environmental and human realms in the face of climatic and social changes. It was determined that architecture as a healing aid could be manifested within the community with inclusive design principles, the built form determined by the creative energies of local community members. The programmatic functions within this centre would then continue to nourish this creative healing spirit.
\end{abstract}




\section{Acknowledgements}

This work is dedicated to the communities of Nunavut, with particular gratitude to the people of Cape Dorset and Sanikiluaq who welcomed me with open arms. I greatly appreciate the contributions of the workshop participants: Kristiina Alariaq, Mukshowya Niviaqsi, Mialia Oqutaq, Ipayaqa Oqutaq, Makitak Pingnartuk, Annie Mannius Pitseolak, Elee (Black) Pootoogoo, Silaqqi Quvianaqtuliaq, Kanayuk Salomonie, Toonoo Sharky, Simgak Suvega,

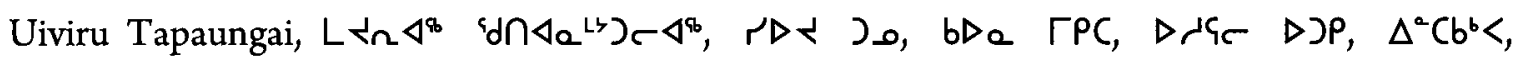

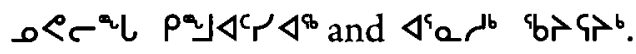

I acknowledge funding from the Government of Canada Program for International Polar Year as part of the project PPS Arctic Canada. This project is a product under the IPY core project PPS Arctic as part of the International Polar Year 2007-2008, which was sponsored by the International Council for Science and the World Meteorological Organisation. Further, I acknowledge the Government of Canada Northern Scientific Training Program (NSTP) for their generous funding.

Acknowledgements would not be complete without recognising the powerful support from my family and friends. I would particularly like to thank Aaron Hughes, Renee Hynes, Jessie and Richard Smith, and Edward Solodukhin for their particular efforts reviewing, editing and providing general support.

Disclaimer: Any errors are the responsibility of the author - not the participants 


\section{Contents}

Abstract ii

Acknowledgments iii

List of Illustrations $\quad v$

Introduction 1

Architecture, Culture and Healing 3

$\begin{array}{ll}\text { Methodology } & 7\end{array}$

$\begin{array}{ll}\text { Site } & 12\end{array}$

Physical Analysis 13

Social Historical Analysis $\quad 16$

Contemporary Housing Situation $\quad 22$

Material Considerations $\quad 29$

Case Studies $\quad 37$

Sápmi in Nordic Europe 37

Eielson Visitor's Center, Alaska, USA 40

Temppeliaukio Kirkko, Helsinki, Finland 42

Design 47

Initial Concept $\quad 47$

Local Designs $\quad 49$

Hybrid Designs $\quad 60$

$\begin{array}{ll}\text { Potential } & 71\end{array}$

Housing $\quad 71$

Propagation and Awareness $\quad 72$

Workshop Studio $\quad 72$

$\begin{array}{ll}\text { Conclusion } & 75\end{array}$

$\begin{array}{ll}\text { Bibliography } & 77\end{array}$

Appendices $\quad 82$ 


\section{List of Illustrations}

Fig. 1 Workshop Participants, Cape Dorset Community Justice Centre, December 8th, 2008. Photograph by Elee (Black) Pootoogoo

Fig. 2 Scenes from the Belcher Islands. Photographs by author.

Fig. 3 Sanikiluaq Community Museum located within Nuiyak School, Sanikiluaq, Nunavut. Photographs by author.

Fig. 4 Various exhibitions as part of the Sanikiluaq Community Musem. Photographs by author.

Fig. 5 Map of Canada. Image by author.

Fig. 6 Freshwater ice windows. Source: C.M. Cato photograph f21, \#162, The British Museum.

Fig. 7 Drawing of freshwater ice windows. Source: Hall 1864:269.

Fig. 8 Snowhouse plans, sections and perspectives. Source: Boas 1888:491-492 and 495-497, 1901:140; Franklin 1823:267; drawn by Jeanne E. Elliss. Reinhardt and Lee 1997:1795, courtesy of Cambridge University Press; Mathiassen 1928:77; Jenness 1922: 12-25, Pls. 3A-B; Stefánsson 1913:pls. opp. pp. 170, 256.

Fig.9 Qarmaq. Source: Boas 1888: fig 498zx.

Fig. 10 Summer Tent. Source: Bilby 1923: 73.

Fig. 11 Tents at Aberdeen Bay, 1968. Source: Rochon 2005: 32.

Fig. 12 Reconstruction of a Thule Culture pit house at Resolute. Source: Rochon 2005: 32 . 
Fig. 13 Reconstructed village, Lakselvbukt, Norway. Photographs by author.

Fig. 14 A Sámi log cabin and interior, Lakselvbukt, Norway. Photgraphs by author.

Fig. 15 Eielson Visitor's Center Roof Terrace. RUM Architects. Source: http://www.rim-ak.com/portfolio/portfolio_project.asp?ProjectID $=60$

Fig. 16 Eielson Visitor's Center. RIM Architects. Source: http://www.rim-ak.com/portfolio/portfolio_project.asp?ProjectID=60

Fig. 17 View of Alaska Range from the Roof of the Eielson Visitor's Center. Photograph by author.

Fig. 18 Green Roof Blending in with the Natural Environment. Photograph by author.

Fig. 19 Details of the Eielson Visitor's Center. Photographs by author.

Fig. 20 Section through Temppeliaukion Kirkko, Helsinki, Finland. Source: <http://www.temppeliaukio.fi/>

Fig. 21 View of Temppeliaukion Kirkko from above. Source: <http://www.temppeliaukio.fi/>

Fig. 22 Temppeliaukion Kirkko. Photograph by Jessie Smith.

Fig. 23 Details of Temppeliaukion Kirkko. Photographs by Jessie Smith.

Fig. 24 Preliminary Plan and Section with Sketches. Image by Author.

Fig. 25 Plan and Elevations. Image by Annie M. Pitseolak.

Fig. 26 Plan and Roof Plan. Image by bDa ГPC (Qauna Makkigak).

Fig. 27 Plan and elevation. Image by Aranasuk Laisa. 
Fig. 28 Plan and perspective. Image by Mayureak Quvainaqtuliaq.

Fig. 29 Drawing of a Mobile Cultural Healing Centre. Image by Mialia Oqutaq.

Fig. 30 Drawing of a tent. Image by Mialia Oqutaq.

Fig. 31 Elevation, plan and roof plan. Image by Uiviru Tapaungai.

Fig. 32 Elevation/perspective. Image by Silaqqi Quvianaqtuliaq.

Fig. 33 Second Iteration: plan. Image by author.

Fig. 34 Parti drawing. Image by author.

Fig. 35 Plan. Image by author.

Fig. 36 Section. Image by author.

Fig. 37 Sketches: Different uses. Image by author.

Fig. 38 Sketches: Seasonal uses. Image by author.

Fig. 39 Carry-on Model. Images by author.

Fig. 40 Virtual Model Stills. Images by author.

Fig. 41 Variations of a Cart from competition submission. Images by author. 


\section{Introduction}

There is still a place that feels as though one is standing on the edge of the world. Whales breathe heavy, frolicking between icebergs in the smooth ocean beyond. A sudden blast thunders across the surface of the waters from the distant mainland and reverberates between the lichenblackened mountains. An odd intrusion into the tranquility, the mysterious sound could be a gun shot, or the blast at a distant mine. It's a sudden reminder that the region is changing, that this vast new frontier is not so far from the world beyond, that it too is in the firm grasp of global reach. The nearby hamlet didn't exist a century ago, and the land was then occupied in a different manner. Today, twenty-five tiny settlements lay scattered immeasurable distances in the vast and diverse terrain of Nunavut. They are populated with people of equally diverse backgrounds, but mainly Inuit who had traditionally populated the sprawling land and sea to the rhythm of animal migrations and to the metronome of the seasons. The fluctuating tundra boasts an incredible array of biodiversity and geo-diversity that annually transforms from a seemingly barren expanse of snow and ice into a verdant living land. The people who live here yearn to maintain their relationship with the outlaying expanses with which only generations ago they were intrinsically connected. The establishment of settlements in the mid-twentieth century created a schism in which southern building typologies, community-planning ideals, and economic and social regimes were imposed upon a radically different cultural fabric, resulting in tear. The objective of this project is to re-discover the original connections between inhabitant 
and environment in an architectural sense and co-design an appropriate architectural response within a framework of changing arctic variables such as culture, society, climate, and location.

The program, a design for a cultural healing centre, is proposed for the Nunavut community of Cape Dorset, also known as Kinngait. The proposal comes at the behest of its citizens to propagate culture, engender civic engagement and find strength in local people as a tool or resource to build a strong future rooted in the flux and stability of culture. This paradigm would ideally manifest principals transferable unto housing and other civic buildings. Housing in particular is in dire shortage in Arctic communities; there are not enough homes, many of those that exist are in disrepair, and even the best homes are lacking in that they are estranged from their regional ancestral history. Further, the communities themselves in these remote areas are in need of reconsideration after decades of 'southern' planning and codification. 'Southern' typically refers to the Euro-Canadian, Western or North American lifestyle from the perspective of the people in the North, mainly above the $60^{\text {th }}$ parallel. The current living conditions in the majority of arctic communities are below the standard of living in relation to the rest of Canada. There are very fragile cultural, social and environmental considerations in these locales that pose a challenge within the current economic and political climate. 


\title{
Architecture, Culture and Healing
}

\author{
"...We can surely look to a positive future for cultural reclamation and all the healing \\ that goes with it." - Joy Hendry ${ }^{1}$
}

The people of Cape Dorset, and specifically the community justice and healing teams, have long wanted a building that acts as a vessel of change - a place where local culture is nurtured, regenerated and expressed in new ways to restore community confidence as well as engaging remediation at the individual level. With a backdrop of heavy social, cultural and environmental changes, the challenge is to ensure that architectural manifestations appropriately reflect a people and their efforts to mend past tribulations with intentions of healthy cross-cultural community building. Re-instilling the inherent value of Inuit language and culture and the stories they carry is vital to cultivating a sense that life has meaning, even when these shift and transform with time, technology and modernity. ${ }^{2}$ The ability of an Indigenous people to trace their cultural traditions, to build them into a blueprint for life and for the education of their children, and to draw on them in all kinds of creative ways is to reclaim an identity that had been severely threatened. ${ }^{3}$ This in turn enables the Inuit as well as informs other peoples of the vitality and lively culture that co-exists with their own. ${ }^{4}$ This is in contrast to convergence theory in which all cultures assimilate or are completely obliterated by one dominant monoculture by the effects of rampant globalisation. ${ }^{5}$ In line with Canadian ideals of multiculturalism and pluralism, life in the Far North equally benefits from having citizens well connected to their cultures as well 
as participating in the greater Canadian dialogue. There is instead a discourse on the need for reclaiming culture and benefiting from its healing power. ${ }^{6}$

To have a truly inclusive and culturally appropriate response to these issues requires close collaboration and discussion with the people that live in the community. The proposed building thus becomes a hybrid derivative of traditional Inuit and Euro-Canadian knowledge, spatial design concepts and techniques. Consequently it serves as a paradigm for healing the schism that exists between contemporary community development and appropriate culturally responsive solutions.

Culture shapes all our thinking, imagining and behaviour according to former United Nations Secretary General Javiér Perez de Cuéllar as noted in his introduction to the Report of the World Commission on Culture and Development:

\footnotetext{
"It is the transmission of behaviour as well as a dynamic source for change, creativity, freedom and the awakening of innovative opportunities. For groups and societies, culture is energy, inspiration and empowerment as well as the knowledge and acknowledgment of diversity... we must learn how to let it lead not to the clash of cultures, but to their fruitful coexistence and to intercultural harmony."
}

This healing centre must therefore be a place that allows for a variety of endeavours that harnesses this positive creative energy. As culture is to cultivate and it is necessary to human creativity, for in our climate of rapid change, individuals, communities and societies can adapt to the new and transform their reality only through creative imagination and initiative. Here we 
must use creativity in its broadest sense, to refer not only to forms and objects of artistic merit, but to extend into every possible realm - business, education, industry, and community development. $^{8}$

This creativity has been absent in the housing design and urban planning in much of the world that often neglects minority groups. Exclusion is sometimes literally built into structures and communities. ${ }^{9}$ It is quite evident that an appropriate architectural response must include members of these groups to actively participate in all phases of community development to determine the most truthful design solutions. This pertains to various scales of land use from the private house to larger public spaces and all realms in between. With appropriate physical development, members of a community will also be given opportunities in human development, that is measured in political, economic, cultural and social freedom as well as opportunities for being healthy, educated, productive, creative and enjoying self-respect and human rights. ${ }^{10}$ 


\section{Notes}

1 Joy Hendry. Reclaiming Culture: Indigenous People and Self-Representation. New York: Palgrave Macmillan, 2005.

2 Kim Crockatt and Suzanne Smythe. "Building Culture and Community: Family and Community Literacy Partnerships in Canada's North.” Nunavut Literary Council. 06 January 2009.

http://www.nunavutliteracy.ca/english/resource/reports/building/15.htm

${ }^{3}$ Hendry, p 196.

${ }^{4}$ Hendry, p 196.

${ }^{5}$ Hendry, p 2-3.

${ }^{6}$ Hendry, p 4.

7 Javier Pérez de Cuéllar, et al. Our Creative Diversity: Report of the World Commission on Culture and Development. France: UNESCO Publishing / Oxford \& IBH Publishing Co, 1995.p 10.

${ }^{8}$ de Cuéllar, et al., p 78.

9 Inclusion by Design: Equality, Design and the Built Environment. Commission for Architecture and the Built Environment (CABE) London. November 27, 2008.

${ }^{10}$ de Cuéllar, et al., p 7. 


\section{Methodology}

The establishment of an appropriate architecture can only be resolved with the full involvement of local people in the design and decision process for a fuller cultural understanding as well as healing rifts between dominant and minority cultures.

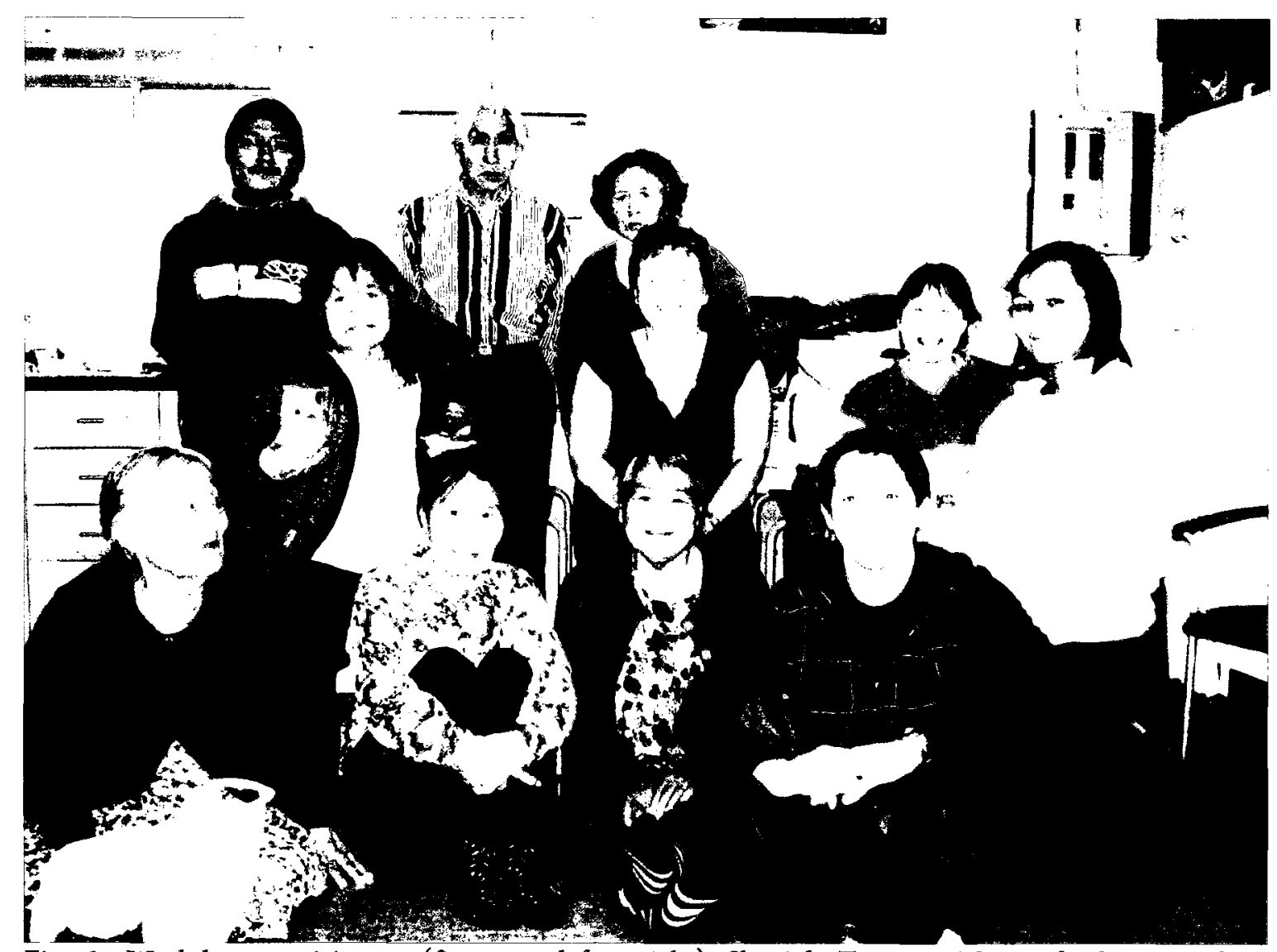

Fig. 1: Workshop participants (first row left-to-right) Sheojuk Toonoo, Mayureak Quvianaquliaq, Novalinga Kingwatsiak, Morgan Ip (second row) Quana Mikkigak, Kristiina Alariaq, Mushowya Niviaqsi, Uiviru Tapaungai (top row)Toonoo Sharky, Simgak Suvega, Kanayuk Salamonie 
A series of consultations began with the Cape Dorset healing team responsible for the program of the research. Design charrettes were held in Cape Dorset and attempted in another Nunavut community, Sanikiluaq. The workshops in Cape Dorset generated several designs and provided indications as to what the community desired in a cultural healing centre. The discussions revealed basic need for space within the community at all programmatic levels. More importantly, the meaning behind these functions was made clear - healing would only be possible with the re-discovery of traditional culture that has been disrupted with swift social, economic and environmental changes. The active participation of community members in the design of a cultural healing centre is but a step towards this goal. Sanikiluaq, on the other hand, yielded a different outcome in regard to architectural dialogue and community participation.

Sanikiluaq is situated in the Belcher Islands, an archipelago in the south-eastern corner of Hudson's Bay. The small community is sheltered by Eskimo bay, huddled amongst the undulating hills and island expanses that extend like fingers between long strands of water. A different physical geography provides a different material pallette, including soft soapstone quarried on nearby Tukarak Island and hauled in by boat. Potential exists here to work with the people and land to create new architectural spaces in a unique, local context. 


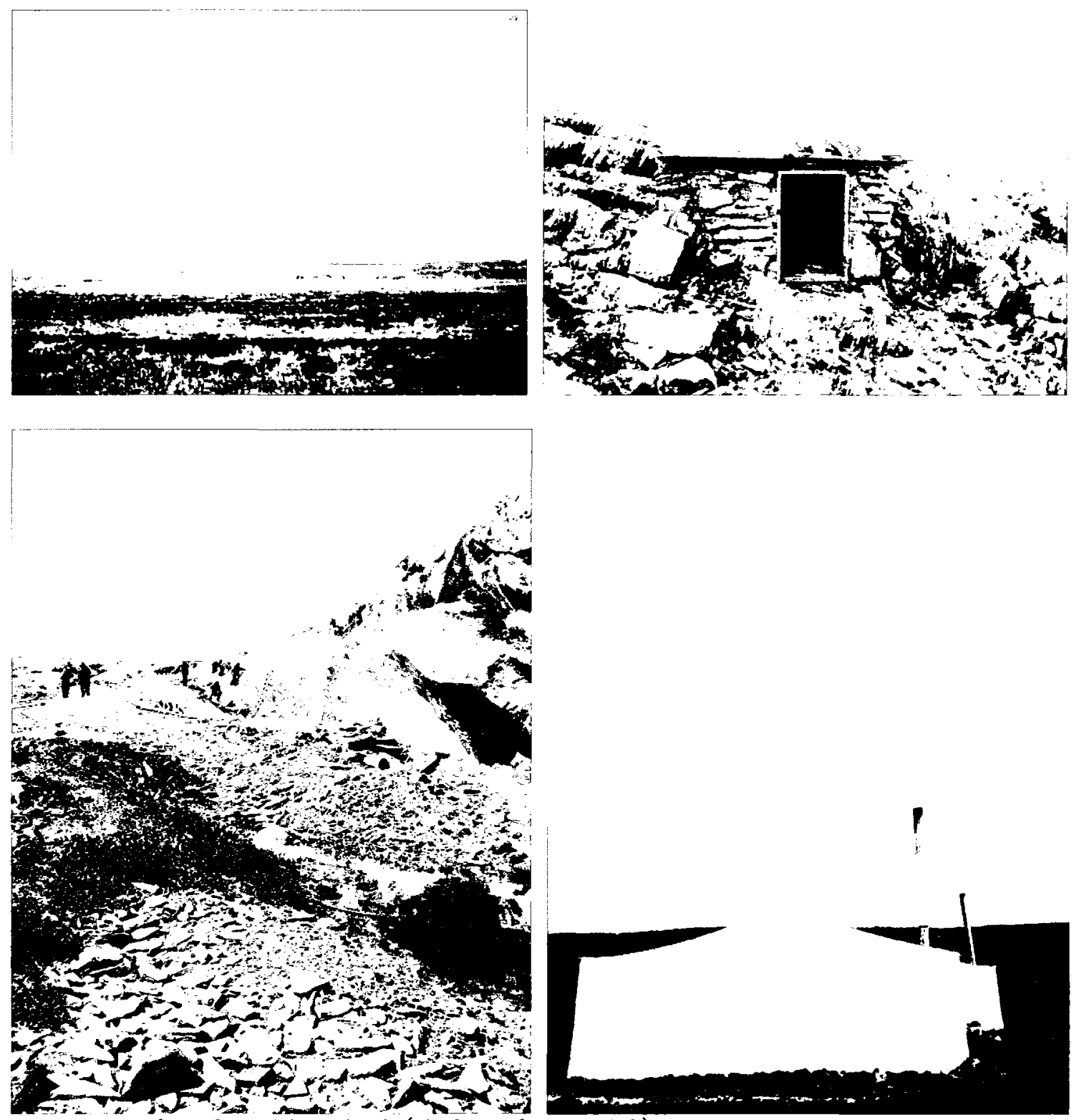

Fig. 2: Scenes from the Belcher Islands (clockwise from top left): an Arctic rainbow, a reconstructed stone hut in Sanikiluaq, summer tents, the soapstone quarry on Tukarak Island.

The community was approached with an undefined building program in a hope that one would emerge in the anticipated dialogue, whereas the community of Cape Dorset had long vocalised a need for a specific building - the cultural healing centre. A local coordinator in Sanikiluaq had the project announced to the community on the local radio station. The council chambers were 
booked for the day and pads of drawing paper, pencils, drafting supplies, crayons and trace were arranged upon the tables that formed a ring. Not one person showed up to the chambers with the intent of participating in a dialogue of architecture in the community. There was, however, a steady trickle of community members who arrived to contribute to a separate project. The focus of the day had shifted elsewhere.

Why had this occurred? Informal discussions with many community members revealed that there was a desire to create a better community with buildings that reflected the people; there was also a plethora of potential programmatic spaces that were wanted, however, there was no singular, uniting building program that stood out or was unanimously requested at the time. This is not to say that there was no internal impetus for community growth in a culturally and locally appropriate manner - a community museum already exists in the local school with an aim to preserve and promulgate local culture - but that perhaps the method used to introduce such dialogue was ineffective in Sanikiluaq.

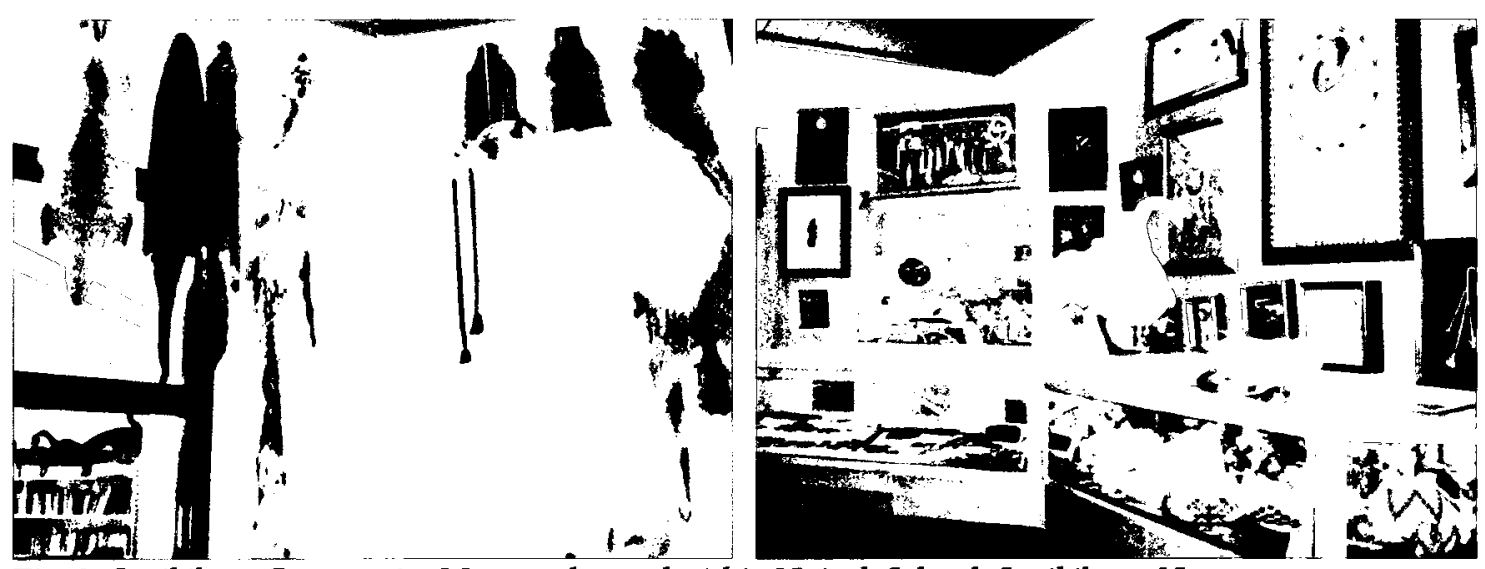

Fig. 3: Sanikiluaq Community Museum located within Nuiyak School, Sanikiluaq, Nunavut. 


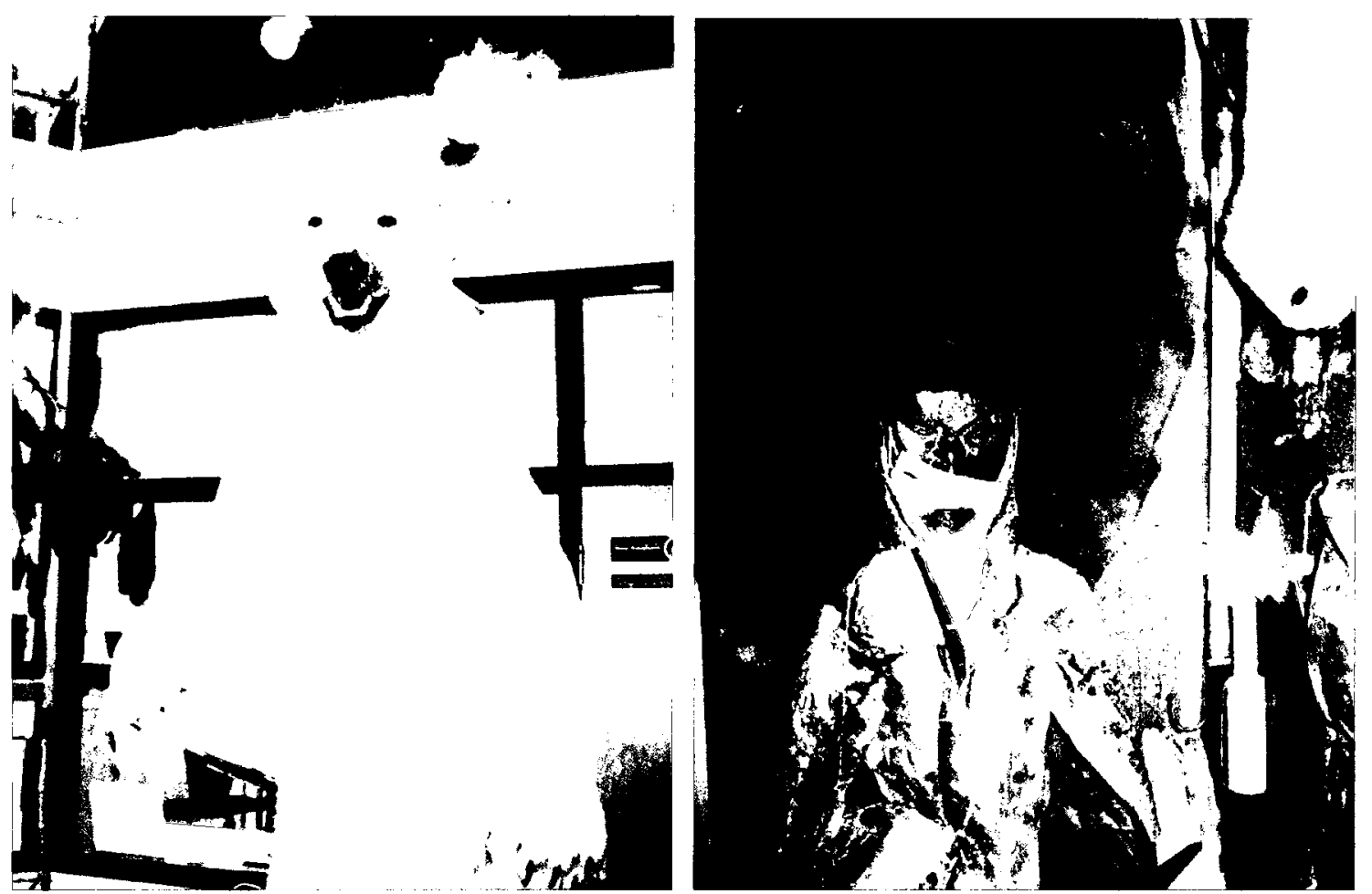

Fig. 4: Various exhibitions as part of the Sanikiluaq Community Museum.

Cape Dorset, on the other hand, had a clear and set objective; it was much easier to become an active agent of design and dialogue. Further, and perhaps more importantly, there was already an existing relationship between researchers at Carleton University and the Cape Dorset community. This established trust may have been influential in securing a new dialogue with an architectural focus, whereas the relationship in Sanikiluaq was nascent and such connections were not fully developed. This leaves room for future engagement and potential cross-cultural collaborative discussion and design in that community. Cape Dorset and its program for a cultural healing centre is thus the main design focus of this venture. 


\section{Site Analysis}
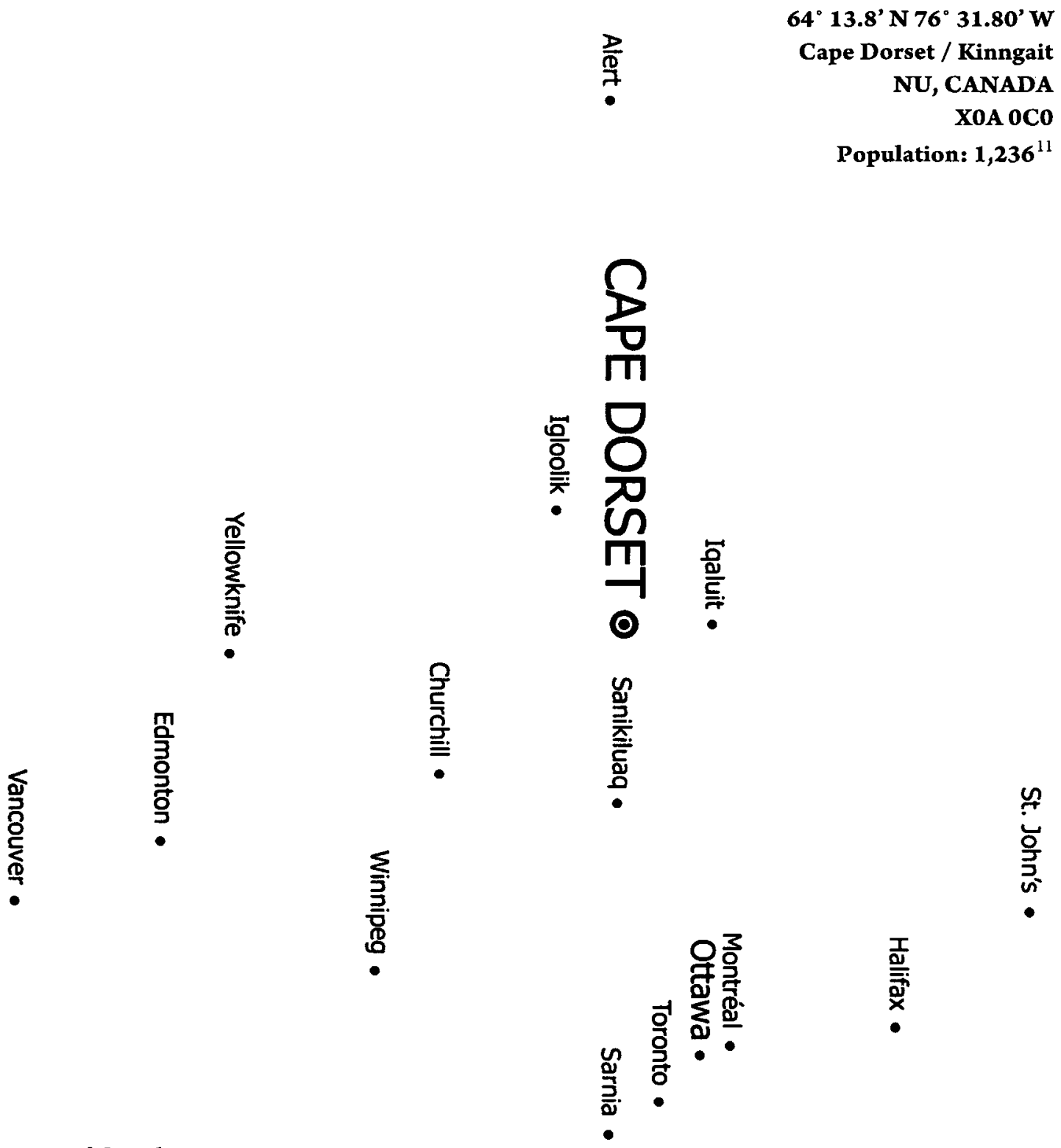

Fig. 5: Map of Canada

The site analysis of Cape Dorset is an investigation of all variables that are encountered when considering an architectural interface between human sensitivities and a fragile tundra biome. There are more than physical properties that affect a building, as the social and economic constructs of these communities dictate the building typologies that develop. 


\section{Physical Analysis}

The community of Cape Dorset is nestled between mountains of granite and quartz. Serpentine, marble and soapstone of varying qualities are all found in the region, and these materials are widely used for local sculptural carvings. Marble, and serpentine which is similar in character and formation to marble but softer, can be used in interior architecture as facings, thin or thickset paving, casework and furniture. They can also be used in exterior for facings and paving, but are susceptible to erosion from atmospheric acids. ${ }^{12}$ Soapstone is extremely dense and resistant to acids, and has frequently been used for countertop material and casework. ${ }^{13}$ However, it may also be used for the facings of buildings.

The bedrock is at surface level in many of the knolls in the community, and in the alluvial areas between there is permafrost. The recorded extremes are $-42.8^{\circ}$ to $25^{\circ}$ Celsius. Average temperature in July is $12^{\circ}$, whereas the January average is $-23^{\circ} .{ }^{14}$ Snow depth is at its deepest in April averaging $60 \mathrm{~cm}^{15}$, and of course this depth depends on location in the hamlet. The maximum recorded snow depth was $147 \mathrm{~cm}$ in April. The average wind direction is mainly from the West with prevalence from the East in June and July, and a November average from the Northeast.

The tides are very high, and nearby monitoring stations record tides ranging from around 4 to 11 metres in difference. ${ }^{16}$ There is a small wharf in the bay, but it is unusable at low tide. Boats 
anchor in the deep water and dinghies are used to traverse to the land at high tide. Sea transportation is thus completely reliant on the tidal cycles.

The flora is incredibly diverse. Shrubs, grasses, succulents, berry bushes and dwarf willows subsist mainly on a thin active layer of soil, as the permafrost and bedrock are near surface level. There are no large trees, and agriculture is non-existent. The soil is suitable for growing crops, but the inclement weather does not encourage extensive farming methods.

Imported fossil fuels provide all current energy needs in Nunavut. Qulliq Energy Corporation is the only energy corporation in Canada without developed local energy resources or regional electricity transmission capability, creating a situation of massive fossil fuel dependency. Each community in Nunavut has its own independent electricity generation and distribution system. There is no back-up grid. ${ }^{17}$

Given the circumstances, current buildings must be highly effective at using the energy available in order to reduce costs associated with complete dependence on foreign sources of energy. There are great potentials to localise energy production: and indeed these steps must be not only explored but actively pursued immediately to hasten the self-sufficiency and resilience of the community. The longer this is ignored the greater the risks of failure of the system with impacts on health and well-being of the inhabitants. 
The power of the tides in the region is a potential energy source for the community. There are also powerful wind gusts across much of the arctic, which may be harnessed with turbines. There is also the opportunity to create energy with the confluence of saltwater and freshwater that is available on all coastal communities, as are all but one in Nunavut. ${ }^{18}$ Localising the source of energy in the community, as well as the maintenance and continuance of such technologies would work towards community self-sufficiency. This may involve remarkable user-friendliness or a continually active training program that ensures that there are members of the community able to maintain the technologies, if not refine them. These discussions must take place at a community level as well to ensure that the people are supportive of all that transpires there.

The natural resources in the arctic are limited in relation to more temperate regions, and the unique limitations thus created are belied by one critical element that makes building and living in the north not only possible, but exemplary - the people. Architect Douglas Cardinal summed up this exact sentiment, "Current thought is slowly coming around to the Native way of understanding that the best natural resource is the individual being." ${ }^{9}$ 


\title{
Social Historical Analysis
}

\author{
"What gives a place its specificity is not some long internalized history but the fact that it \\ is constructed out of a particular constellation of social relations, meeting and weaving \\ together at a particular locus." - Doreen Massey ${ }^{20}$
}

The history of the peoples that live in the Arctic is quite extensive. There was an initial inhabitation of the vast region in Paleolithic times as early as 3,000 B.C.. With changes in climate, populations migrated, waxed and waned. The Thule are believed to have traversed the Bering Strait around $1000 \mathrm{AD}$ and stretched out across the tundra eastward. Modern Inuit societies are descended from these Thule people who had reached Greenland around 1200AD..$^{21}$ They cohabited with the earlier arriving Dorset people for several hundred years without much interaction despite sharing related languages. By the sixteenth century the Dorset disappeared, likely by assimilating with the Thule. ${ }^{22}$ It is believed that the descendant Inuit borrowed many aspects of house building from the previous inhabitants of the Arctic lands. Southerly or seaward orientation, semi-subterranean house floors, raised sleeping platforms, cold-trap tunnels or passageways, domed snow houses and tents are believed to be derived of the Thule. $^{23}$

Inuit life before settlement in the mid-twentieth century was semi-nomadic, semi-sedentary; determinant on the availability and migrations of game, as their diet was overwhelmingly based on animal protein and fat. ${ }^{24}$ The Inuit lived in tents in the summer and in half-buried sod or 
stone houses, called qarmaq ${ }^{25}$, through much of the winter. Those in the Central Arctic eventually switched to snow houses as their primary winter house type. ${ }^{26}$ Winter houses in Labrador and Greenland favoured stone or wood communal houses. The snow winter houses of the Central arctic reflect the lack of driftwood available and also inform of the Inuit lifestyle. Proximity to marine food sources required habitations to constantly move near or on the ice. Snow houses were efficient to build especially as the Inuit cooperated in the hunt for the benefit of all. ${ }^{27}$ The snow house differed according to regions. There were some built up layer by layer, and some with a spiral technique. In Alaska there were even instances of rectangular snow houses. Some of the tunnels were designed domed like the house proper and others had straight walls with horizontal roofs. The location of these snow houses and communities was also specifically determined. They were usually situated on east- and south-facing slopes to avoid the wind and snowdrifts. The location also had to have just the right density and consistency of snow to be cut and built properly. In fact, the location and proximity to materials seemed to be the prime justification for the location of a dwelling. ${ }^{28}$ There was also a hole cut into the snow house upon completion, in which a fresh water ice pane was placed as a window.

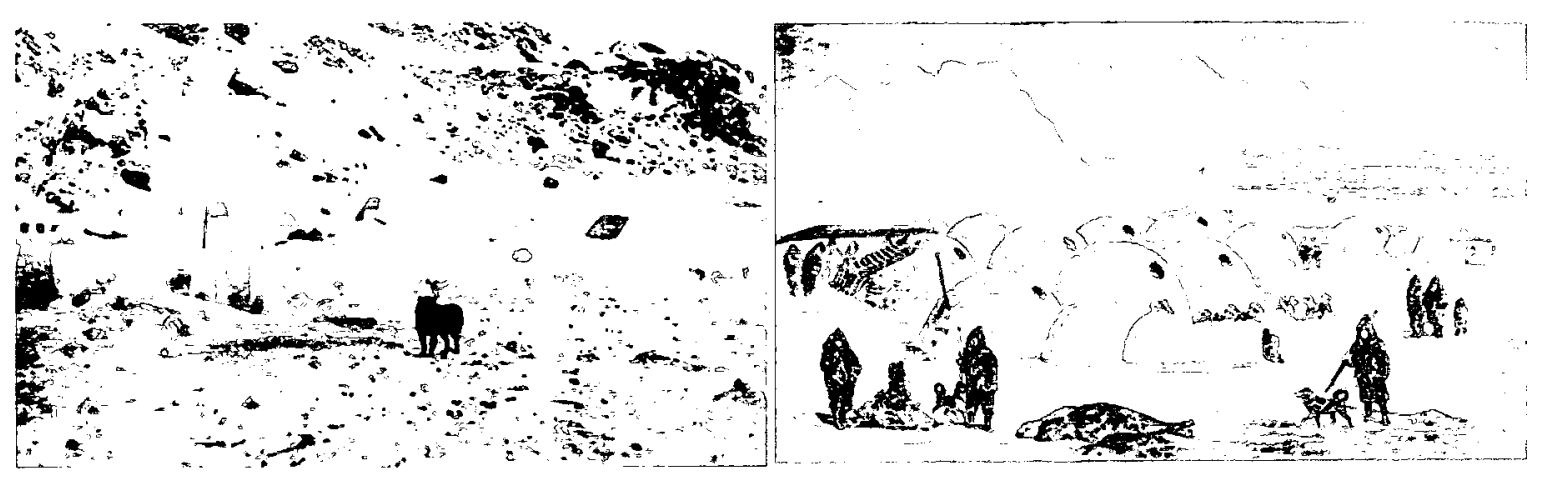

(left to right) Fig. 6: Photo showing ice windows, Fig. 7: Drawing showing ice windows and orientation 
Traditional northern communities, when they would form, were inherently sustainable. The communities in the north now rely on diesel power; the fumes of which waft through the villages. The waste from the homes piles up in dumps open to the tundra, collecting and stagnating in relative proximity to the settlements. Sometimes they even burn, releasing toxins into the air. This situation differs from previous eras, when all materials and energy sources were from the land, and the nomadic lifestyle ensured periods of time for waste to decompose.

The form of the traditional northern house would alter with the seasons, with the coming and going of inhabitants and in response to external and internal conditions such as freeze-up, thaw, animal migrations, and social situations. The configurations of a winter snow village expressed in material form the social structure of a community at a given moment. A single dwelling could stand alone, as was often the case. Just as often, the house served as a basic unit of a larger complex of structures conjoined by a central domed space with a common passageway to the outdoors. $^{29}$

The snow house was the whole setting for life, connected to other homes with corridors to save from external traversing in the harsh winter cold. ${ }^{30}$ The community and house forms would also change with group size by simply cutting a hole and adding a new dome, or closing a doorway off with relative ease. ${ }^{31}$ 

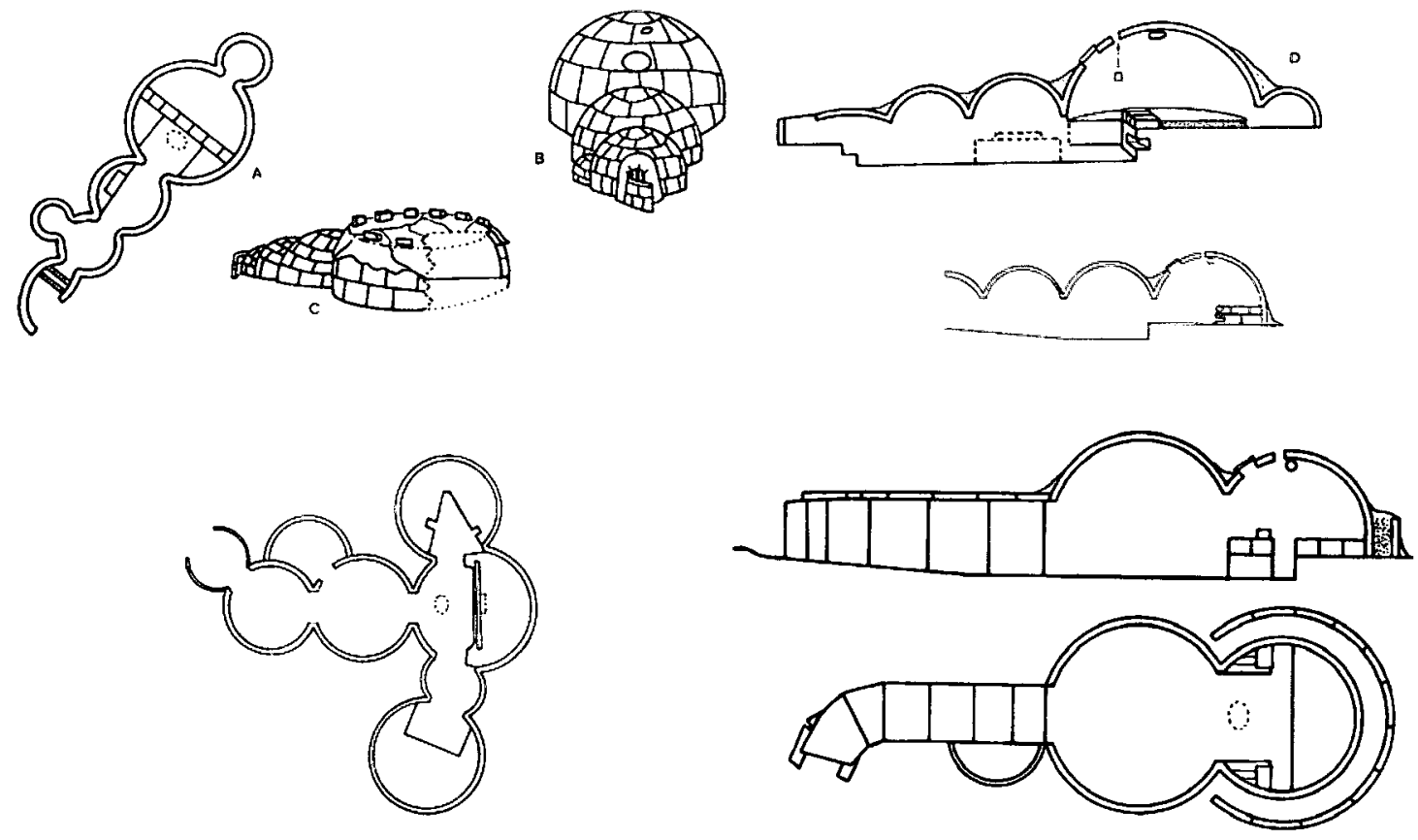

Fig. 8: Various snowhouse plans, sections, and perspectives

The autumn house, or qarmaq, was built before there was sufficient snow to build snow houses, but once it was too cold for tents. This semi-permanent swelling was small with walls of stone, turf, moss and whale bones, and sometimes wholly or partially of ice slabs. ${ }^{32}$ The entrance was two feet high and ten feet long made of stone covered in turf. Qarmat were often used more than once, and simply cleaned out and intermittently reoccupied. The rafters were made of whale ribs or mandibles, and covered with skins to form a roof. The sleeping platform occupied the much of the rear half, and in the case of shared family dwellings, a skin wall was put up to divide the space. A gut window illuminated the space more than the faint glow emanating through the skins. ${ }^{33}$ Tents were used in the summer, with some regional differences. On Baffin Island, there 
was usually a half conical arrangement of poles for the sleeping quarters at the back and a pole bipod at the front. ${ }^{34}$
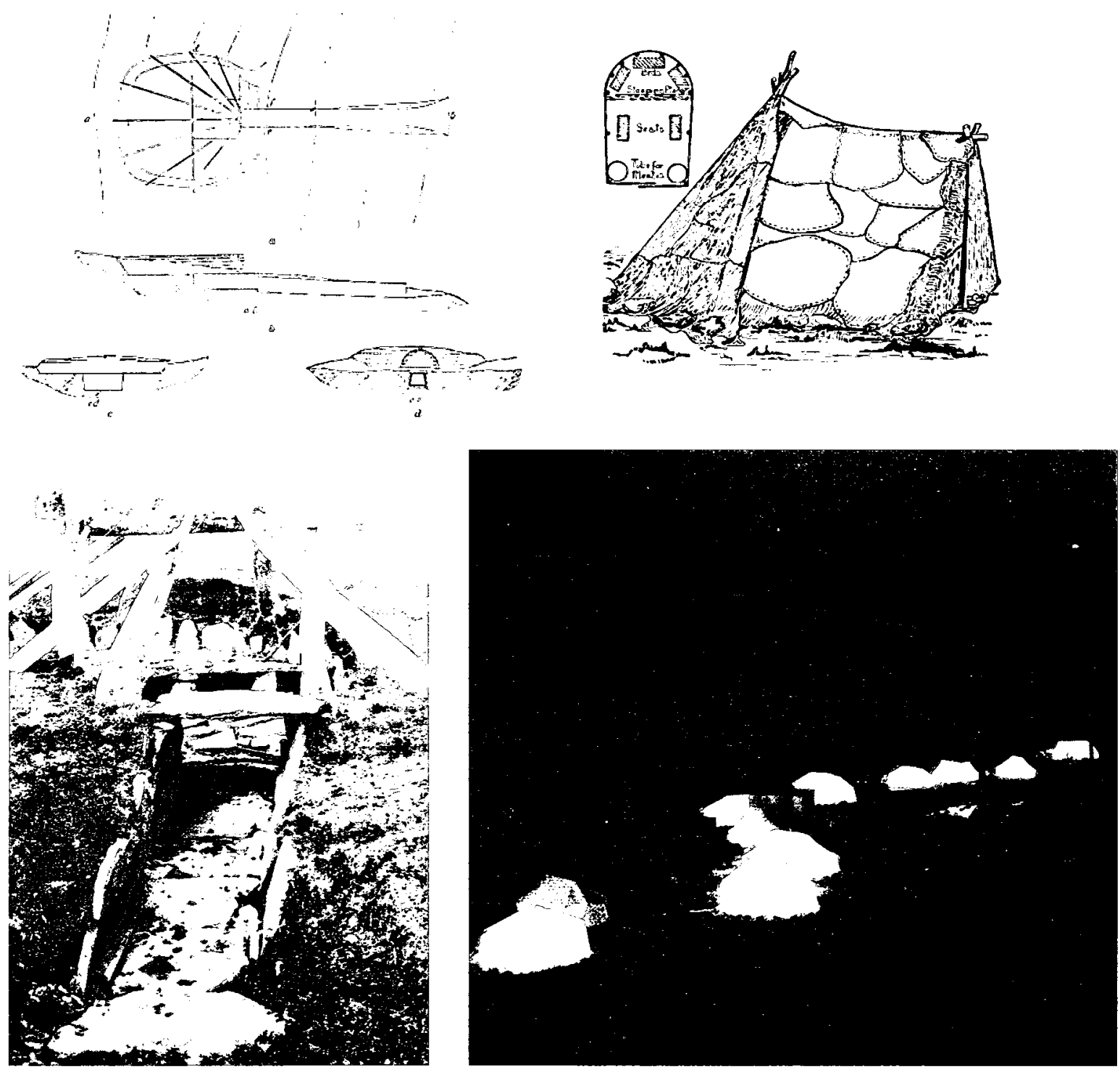

(clockwise from top left) Fig. 9: Qarmaq, Fig. 10: Summer tent, Fig. 11: Tents in the Cape Dorset area (1968), Fig. 12: Reconstruction of a qammaq at Resolute 
The Inuit did not consider houses to be private property, and there were no feelings of obligation to return to the same site each year, especially as game was likely to have been depleted and needed to recover. ${ }^{35}$ When the summer came a demographic shift occurred, as group members wearied of each other's company, and nuclear units would depart in different directions. This represents a residential pattern that reflects socio-cultural forces as much as environmental ones. ${ }^{36}$

Current housing and public spaces deny this, though there has been recent efforts to address this. Bill Temple of the Canadian Housing and Mortgage Corporation has investigated the approach of cultural appropriate housing with a focus on the spatial dimensions of the Inuit home. ${ }^{37}$ In a similar approach, his community based research involving local people was necessary not only to discern what properties were essential in designing appropriate housing, but also the act of collaboration itself can be seen as an appropriate methodology of crosscultural learning.

In contrast, current settlements resemble remote, isolated suburbs typically found in the south. One could suggest that their downtown core is the capital Iqaluit, a relatively long flight from most Arctic communities, but the main node of government services and activity in the territory with a population of approximately 30,000 . The schools, offices and other services are generally placed sporadically throughout the small communities. The house is a more enclosed and private part of the settlement. Houses are separated by sizeable distances, for ostensible sanitary 
and fire safety regulations. This makes traveling to schools, health clinics or other services more arduous, especially without paved roads, sidewalks and a limited number of vehicles.

The movement between settlements is also an important consideration in community evolution. People move to where there are more opportunities, better schools, etc... The trend has been for smaller communities to become smaller and even vanish, while medium and large sized communities grow. This leaves large stretches of coastline to be uninhabited as never before, even though there is still ample game available in these newly abandoned areas. The larger communities become outstripped of available game and the indigenous populations become even more reliant on western amenity. ${ }^{38}$ The sparsely but thoroughly populated tundra is becoming one of fewer and fewer nodes, or points of habitation with vast stretches of uninhabited spaces in between.

\section{The Contemporary Housing Situation in the North}

The contemporary housing stock in the north resembles houses of the post-war period in the south, and interestingly is a similar response. Prefabricated matchbox houses were set up by the Canadian government in the 50's to accommodate Inuit who were settling. As men had left farms and returned to the city in the south after the war, the Inuit left the nomadic life style to settle in specific nodes that provided health services, schools, stores and the like. However, as opposed to the Canadian south since the war, the marketplace did not have a major impact in housing. In fact, Nunavut is essentially a non-market environment because of high costs 
associated with its remote geography, underdeveloped infrastructure, harsh climate, lack of rail or roads, and high cost of labour and materials. ${ }^{39}$ Therefore, social housing programs in the Arctic region date to as late as the 1960's to when the settlements were being further established. In 1969, when Public Housing construction was suspended across Canada, it continued in the North West Territories (of which Nunavut has since been partitioned) to address these special concerns. ${ }^{40}$ In 1973, non-profit and co-operative housing programs in the south, however, were replacing the Public Housing Programs they continued unabated in the North by the Northwest Territories Housing Corporation. The following decades saw improvements in the quality and energy efficiency in Northern housing, with new models and designs introduced. ${ }^{41}$

In 1986, Nunavut Lands Claims negotiators proposed to take on responsibility for housing as part of the settlement in creating the territory of Nunavut. The Federal Minister at the time rejected their proposal, indicating that it was beyond the lands-based mandate of the Federal Comprehensive Claims Policy in effect at the time. The Government's commitment to housing for Inuit seemed clear and the proposal was withdrawn.

On May $25^{\text {th }}, 1993$, the Government of Canada signed the Nunavut Claims Agreement with the Inuit of Nunavut on behalf of Canada. ${ }^{42}$ Shortly thereafter, the federal government under then Prime Minister Brian Mulroney announced that new construction and acquisition of social housing was to be phased out and responsibility assigned to the provincial and territorial governments, contrary to the advice given by the Co-operative Housing Federation of Canada. ${ }^{43}$ 
The advice was that the federal government should maintain a role in the housing programs as it is such a complex public service industry that necessitates participation of all levels of government. Downloading the entire burden upon the provincial and territorial jurisdictions divides an issue that is common to Canadians everywhere, especially as the fiscal policy and economic powers made by the federal government would affect the housing industry. ${ }^{44}$

Though on-reserve housing programs for other Aboriginal Canadians were maintained or improved, social housing programs for Nunavut ceased, even though the Inuit are recognized as Aboriginal People. ${ }^{45}$ Federal subsidies for operating and maintaining existing units have since been scheduled for phase-out beginning in 2004 and ending in 2037. Though Nunavut will have free-and-clear title to over three thousand units under the Social Housing Agreement, it will have lost almost a billion dollars in funding. ${ }^{46}$

The Nunavut Housing Corporation (NHC) delivers the Public Housing Program throughout all 25 communities in Nunavut with close cooperation with local housing organizations (LHOs) and three empowered municipalities. The later are hamlets that have assumed full responsibility for public housing services in their communities, as negotiated with the NHC. The hamlet office in these communities performs all of the functions traditionally done by an LHO in addition to regular municipal administration. ${ }^{47}$ 
Currently, the NHC struggles to provide adequate housing for the entire populace. Clients who need housing are rated according to set criteria, so that core need applicants get houses first. Applications are done locally, and individual circumstances and geared-to-income rent are considerations to ease the burdens of the cost of living in the north. Tenants will never pay more than $28 \%$ of their disposable income towards rent, and depending on income levels, rents can range from the minimum of $\$ 60$ to the maximum based on the cost of operating and maintaining a unit. Rent is also re-evaluated annually to consider changes in income, and will adjust according to a decrease or increase in income. ${ }^{48}$ Furthermore, the base rent is subject to deductions which provide an allowance for the condition of the unit, overcrowding and community-specific costs of living. Seniors and disabled tenants are able to live rent-free, reflecting Inuit principles of caring for and respecting those unable to do so themselves. Students and youth are also given special considerations with exemptions and adjustments available to promote youth employment and savings, as well as to accommodate the needs of full-time students. Given these considerations, it is shocking that $54 \%$ of the Inuit live in overcrowded houses and $38.7 \%$ are in core need, meaning that they do not live in nor can they access acceptable living. ${ }^{49}$ Multiple families sleep in shifts in houses that are less than 1000 sq. $\mathrm{ft} .{ }^{50}$ If these conditions are ignored, with no action plan in place, overcrowding is expected to increase by $30 \%$ to encompass $70 \%$ of the population. ${ }^{51}$ The permanent house has now become a vital part of living in the North. However, most homes are not owned. 
This idea of house in general is profoundly different than that which has evolved in western industrialized cultures. Though even within Southern cultures the idea varies, the typically accepted view could be synopsised by architecture professor Amos Rapoport: "The dream home is surrounded by trees and grass in either country or suburb, and must be owned, yet Americans rarely stay in it for more than 5 years. It is not a real need, but a symbol. This symbol means a freestanding, single family house, not a row house, and the ideal of home is aesthetic, not functional." ${ }^{2}$ With the adoption of a completely different typology than the traditional cultural expectations of dwelling, social and climatic advantages are lost. Rapoport suggests that in order to be successful, all housing need only to achieve the following four objectives: ${ }^{53}$

1. To be socially and culturally valid.

2. To be sufficiently economical to ensure that the greatest number can afford it.

3. To ensure the maintenance of the health of the occupants.

(In relation to climate traditional housing succeeds, in relation to sanitation it usually fails.)

4. To have a minimum of maintenance over the life of a building.

Taking these objectives into account, the current built houses in Nunavut ignore all of them. To begin, the houses are certainly not socially or culturally valid. Houses are constantly being altered or used by the Inuit that attempt to reflect traditional culture, squeezed into a Southern template. In the 60 's, people often used the living room floor for cutting large game, and the 
bathtub for storage. Even more recently, it has been common to see family members sleeping in the living room, as families traditionally preferred to sleep together this expressed their continued solidarity and the living room was the largest room for this. ${ }^{54}$

In an example of not just re-interpreting the Southern use of space, but actual adjustment of spaces, one Inuit man made many alterations to his home to save money needed to pay for gas, ammunition, and other essential items necessary for hunting and fishing. These included placing skirting around the base of his house to save money on heating bills, and then he left the southern side open so that warmer southern winds would travel under the house. In the winter, he piles snow up against the side of his house that is high enough to provide extra insulation, as there is dead air space under the house. He further replaced the standard front door handle with a heavy duty industrial handle, and spring loaded the door with bungee cords so that it closes automatically. Prior to this the constant stream of visitors to and from his house resulted in the doors being left open, thereby increasing his heating bills. He replaced the 5 gallon toilet with a foot peddle version that uses less water and saves on utility costs. He purchased linoleum to fasten to the lower portions of the walls in the house to prevent damage caused by the scratching and drawing of children. With the traditional open atmosphere in mind, he even suspended a parabolic surveillance mirror in the wall to increase what can be seen in the L-shaped kitchen and living area. ${ }^{55}$ Such are the lengths that some individuals and families undergo to make their southern houses more appropriate to their cultural, climatic, and economic needs. 
In an economic move away from the single detached matchbox house, the NHC is currently building duplexes (see Fig. C), and multiplexes in 3-plex, and 5-plex configurations to optimize the use of limited financial resources, and to provide the highest efficiency in building configuration. ${ }^{56}$ This is possible through shared mechanical facilities and better use of limited land lots, in tandem with traditional closely-knit housing conditions. However, they still deviate from the much more fluid constructs as Edmund Carpenter eludes, "Instead of resorting to boxes, they build complex many-roomed igloos which have as many dimensions and as much freedom as a cloud." ${ }^{57}$ Though the majority of current houses are not successful in terms of affordability, which results in overcrowding and a populace that relies on scarce public housing, there is a goal within the administration to reduce costs. Interestingly enough, absolute homelessness does not exist in Nunavut, as the 'hidden homeless' sleep in shifts within already overcrowded homes of friends and family. ${ }^{58}$

Overcrowding as well as flaws resulting from wooden construction in the harsh, arctic climate jeopardizes the health of the occupants. The maintenance over the life of a building is also at a premium, with operations and maintenance at $\$ 18,000$ per year; expected renovation and expansion costs of existing housing stock is also exorbitantly estimated at $\$ 100,000$ per unit. $^{59}$ Such dire straits will only worsen over time unless a more affordable housing type is found and/or federal subsidies are increased many times fold. 
When considering the design of housing as well as public buildings in the arctic, we must look at the conditions within which it is built. To identify how to ameliorate the dire conditions, we must know what the problem is. What is it that makes building in the north so unaffordable? All materials are imported, and usually only on shipments once or twice a year. The costs of transportation are astronomical considering the vast distances they must travel to be delivered to a very small population (all of Nunavut is less than 30,000 people). Labour is also often at the hands of people from outside the territory. Their expenses also reflect the high costs of living, and therefore labour wages are high. Building can only be done at certain times of year - usually a maximum of 6 months for any outdoor work though even this time frame may be further limited in the high arctic. Utilities are also expensive. Infrastructure that services the buildings is also unaffordable since the houses are spaced out at greater distances than in the south. Lack of appropriate fire prevention services also contributes to this. In regards to health and safety, people who live in poverty are at a greater risk of a disproportionate share of environmental hazards, thereby would benefit most from interventions that promote environmental equity. ${ }^{60}$

\section{Material Considerations}

The divisions that exist between contemporary non-indigenous vernacular architecture and traditional built form are vast. Materials used at present are wood, glass, metal, plastics and various other compounds all sourced elsewhere. External laborers provide much of the construction labour force. The planning and administration is also based on Southern principles 
that are hardly appropriate for Northern locations. The electricity and heating is generated by imported fossil fuels, mainly diesel. Transportation is mechanic and reliant completely on a constant supply of imported fossil fuels and replacement parts. Sewage is trucked from each individual house and building to a series of sewage ponds located up stream from one of the four neighborhoods that comprise Cape Dorset. Buildings are completely reliant upon a constant flow of materials and goods from the outside world, a considerable exploit considering the remoteness of the community.

In comparison, traditional building materials were completely organic and locally abundant including ivory, bone, driftwood, rawhide, fur pelts and skins, sod, stone and snow. ${ }^{61}$ It was the responsibility of each Inuk to know how to build his own dwelling, whether it was a tent, sodhouse, or snow house, and this knowledge and technique was passed down orally from generation to generation. In effect, each Inuk was an architect. The ice house can be regarded as the oldest shelter known to mankind given that the material, shape, spatial and ritual expectations embedded in the concept of the igloo have lasted unchanged for thousands of years. $^{62}$

Materials have traditionally been used with incredible efficiency and for the most appropriate human use. Locally available and potentially available materials are best to be analysed for prospective use in current building. Materials that must be imported should also be evaluated based on their suitability and appropriateness. Stone is the most readily available local material, 
but it has limitations that prevent it from current widespread building practice. Methods of material extraction and reuse will also determine appropriateness in building construction.

Stone is readily available as fieldstone, but the Canadian Shield also reveals itself at the surface in much of the tundra in undulating hills and mountains. Excavation of this hard rock requires extreme environmental consideration, but in limited and carefully selected sites may prove valuable as both foundation and construction or finishing material. It is possible to reduce the effects of foundation construction on neighbouring buildings with the use of diamond wire cutters and accompanying technology. Gathering fieldstone is also more intensive an activity in Cape Dorset and surrounding environs. It lays scattered across the land, but to carry large enough quantities would require heavy equipment. In contrast, Sanikiluaq has vast ancient beaches that have laid wave upon wave of smooth stones with no soil with easy access to transportation to the community. This shows that each community's specific environmental uniqueness would determine a different material palette, resulting in buildings unique to each community.

The buildings of Cape Dorset are all located quite far from each other, and with each incremental distance added as a new building rises, the less likely a person is willing to walk to visit each other, go to school or the community centre. Building denser communities that maintain fire protection with the abundance of local loose or quarried stone materials may ameliorate this. The use of wood imported from the south in much of the building stock 
increases chances of fire, but moreover increases embodied energy and outsources labour. The use of local materials would also address this problem. Should the climate continue to change, and the communities continue to burgeon, a need to reorganize and consider the methods of building in the area grows. 
Notes

${ }^{11} 2006$ Canadian Census http://www12.statcan.ca/census-recensement/2006/dp-pd/hlt/97$550 /$ Index.cfm ?TPL $=P 1 C \& P a g e=R E T R \& L A N G=E n g \& T=302 \& P R=62 \& S=1 \& O=A \& R P P=25$

${ }^{12}$ Mark A. Chacon. Architectural Stone: Fabrication, Installation, and Selection. John Wiley \& Sons: New York 1999. 32-33, 37.

${ }^{13}$ Chacon, 32.

${ }^{14}$ Canadian Climate Normals 1971-2000, Environment Canada National Climate Data and Information Archive website:

http://climate.weatheroffice.ec.gc.ca/climate_normals/results_e.html? StnID=1738\&autofwd= 1 (October 26, 2008)

${ }^{15}$ Canadian Climate Normals 1971-2000, Environment Canada National Climate Data and Information Archive website:

http://climate.weatheroffice.ec.gc.ca/climate_normals/results_e.html?StnID=1738\&autofwd= 1 (October 26, 2008)

${ }^{16}$ Fisheries and Oceans Canada website accessed October 23, 2008 with tide levels compared at monitoring stations at Schooner Harbour (NU), Port de Boucherville (NU), Sugluk (QC) and Kimmirut (NU). Schooner Harbour is the closest monitoring station, though tide levels at various locations in the region would vary depending on geophysical form. For access visit: http://www.waterlevels.gc.ca

${ }^{17}$ Qulliq Energy Corporation Website accessed October 23, 2008 http://www.nunavutpower.com/home/index.php?option=com_content\&task=view\&id=17\&I temid $=32$

${ }^{18}$ Reversed Electro Dialysis (RED) technology being researched at WETSUS, a Dutch water technology institute

Jan W. Post, Hubertus V.M. Hamelers and Cees J.N. Buisman. Energy Recovery from Controlled Mixing Salt and Fresh Water with a Reverse Electrodialysis System. Environmental Science and Technology., 2008, 42 (15), p 5785-5790. http://pubs.acs.org/doi/full/10.1021/es9004224 (Mar 4, 2009)

${ }^{19}$ Douglas Cardinal and Jeanette Armstrong. The Native Creative Process. (Penicton, BC: Theytus Books 1991) 25. 
${ }^{20}$ Doreen Massey. Space, Place, and Gender. (Minneapolis: University of Minnesota Press, 1994) 154.

${ }^{21}$ Lee, Molly and Gregory A. Reinhardt. Eskimo Architecture: Dwelling and Structure in the Early Historic Period (Fairbanks: University of Alaska Press. 2003) 4.

${ }^{22}$ Louis-Jaques Dorais, Quaqtuq : Modernity and Identity in an Inuit Community (Toronto: University of Toronto Press, 1997) 14.

${ }^{23}$ Reinhardt and Lee, 4.

${ }^{24}$ Reinhardt and Lee, 4.

${ }^{25}$ There are variations of this spelling - qammaq, qarmaq,

${ }^{26}$ Reinhardt and Lee, 38.

${ }^{27}$ Reinhardt and Lee, 38.

${ }^{28}$ Leo Zrudlo, "The Design of Climate Adapted Arctic Settlements". Cities Designed for Winter Eds. Jorma Mänty and Norman Pressman (Helsinki: Building Book Ltd, 1988) 87-88.

${ }^{29}$ Reinhardt and Lee, 50.

${ }^{30}$ Amos Rapoport. Housing Form and Culture (Englewood Cliffs, NJ: Prentice-Hall Inc. 1969) 97.

${ }^{31}$ Reinhardt and Lee, 50.

${ }^{32}$ Reinhardt and Lee, 52-53.

${ }^{33}$ Reinhardt and Lee, 52-53.

${ }^{34}$ Reinhardt and Lee, 56.

${ }^{35}$ Reinhardt and Lee, 5 .

${ }^{36}$ Reinhardt and Lee, 5.

${ }^{37}$ Bill Temple. Tradition and Technology: The Designing of Housing for the Arctic. Exploring Domestic Spaces in the Circumpolar North Conference, Tromso Norway. October $2^{\text {nd }}, 2008$. Powerpoint presentation. 
${ }^{38}$ Nelson H.H. Graburn. Eskimos Without Igloos: Social and Economic Development in Sugluk (Boston: Little, Brown and Company. 1969) 222.

${ }^{39}$ The Government of Nunavut (Nunavut Housing Corporation). "Nunavut Ten-Year Inuit Housing Action Plan." Nunavut Housing Corporation. <http://www.nunavuthousing.ca/i18n/english/pdf/10YearHousing\%20Plan_Eng.pdf $>, 12$.

${ }^{40}$ The Government of Nunavut (Nunavut Housing Corporation). "Nunavut Ten-Year Inuit Housing Action Plan.", 3.

${ }^{41}$ The Government of Nunavut (Nunavut Housing Corporation). "Nunavut Ten-Year Inuit Housing Action Plan.", 3.

${ }^{42}$ The Government of Nunavut (Nunavut Housing Corporation). "Nunavut Ten-Year Inuit Housing Action Plan.", 3.

${ }^{43}$ Rapoport. 6.

${ }^{44}$ Rapoport, 6-7.

${ }^{45}$ The Government of Nunavut (Nunavut Housing Corporation). "Nunavut Ten-Year Inuit Housing Action Plan.", 3.

${ }^{46}$ The Government of Nunavut (Nunavut Housing Corporation). "Nunavut Ten-Year Inuit Housing Action Plan.", 3-4.

${ }^{47}$ The Government of Nunavut (Nunavut Housing Corporation). "Public Housing." Nunavut Housing Corporation. <http://www.nunavuthousing.ca/i18n/english/p public.html >

${ }^{48}$ The Government of Nunavut (Nunavut Housing Corporation). "Public Housing."

${ }^{49}$ The Government of Nunavut (Nunavut Housing Corporation). "Nunavut Ten-Year Inuit Housing Action Plan.", i.

${ }^{50}$ The Government of Nunavut (Nunavut Housing Corporation). "Nunavut Ten-Year Inuit Housing Action Plan.", 7.

${ }^{51}$ The Government of Nunavut (Nunavut Housing Corporation). "Nunavut Ten-Year Inuit Housing Action Plan.", 17.

${ }^{52}$ Rapoport, 132-133. 
${ }^{53}$ Rapoport. 129.

${ }^{54}$ Peter C. Dawson. Examining the Impact of Euro-Canadian Architecture on Inuit Families living in Arctic Canada. (Calgary: University of Calgary, 2003) 10.

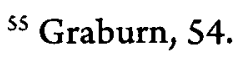

${ }^{56}$ The Government of Nunavut (Nunavut Housing Corporation). "Public Housing."

57 Edmund Carpenter. "Image Making in Arctic Art," in Sign, Image and Symbol, ed. Gyorgy Kepes. (New York: George Braziller, 196) 221.

s8 The Government of Nunavut (Nunavut Housing Corporation) and Nunavut Tunngavik Inc. "Housing in Nunavut Overview." Nunavut Housing Corporation. <http://www.nunavuthousing.ca/i18n/english/h_overview.html>

${ }^{59}$ Nunavut Ten Year Inuit Housing Action Plan, 25.

${ }^{60}$ Inclusion by Design: Equality, Design and the Built Environment. Commission for Architecture and the Built Environment (CABE) London. November 27, 2008.

${ }^{61}$ Papanek, Victor. The Green Imperative: Natural Design for the Real World. New York: Thames and Hudson, 1995. 224

${ }^{62}$ Papanek, Victor. The Green Imperative: Natural Design for the Real World. New York: Thames and Hudson, 1995. 245 


\section{Case Studies}

These case studies are meant to examine precedence in certain relationships, between that of architecture and the land, materials, and social and cultural contexts. These are also compared with previously examined local traditional vernacular building types.

\section{Sápmi in Nordic Europe}

The Sámi (Saami) people of Sápmi, in northern Fennoscandia (Norway, Sweden, Finland and the Kola Peninsula in north-western Russia), though extraordinary in their uniqueness have had similar struggles as the Inuit of the Central Canadian Arctic. Both groups have a history of nomadic living, close relationships with the land, and tenuous relationships with southern colonial influences. Both had comparable vernacular architectures that have given way to contemporary structures (Fig. 13) and we may look at their relationship between tradition and current building to reveal how similar pasts and traditions affect current architectural practice.
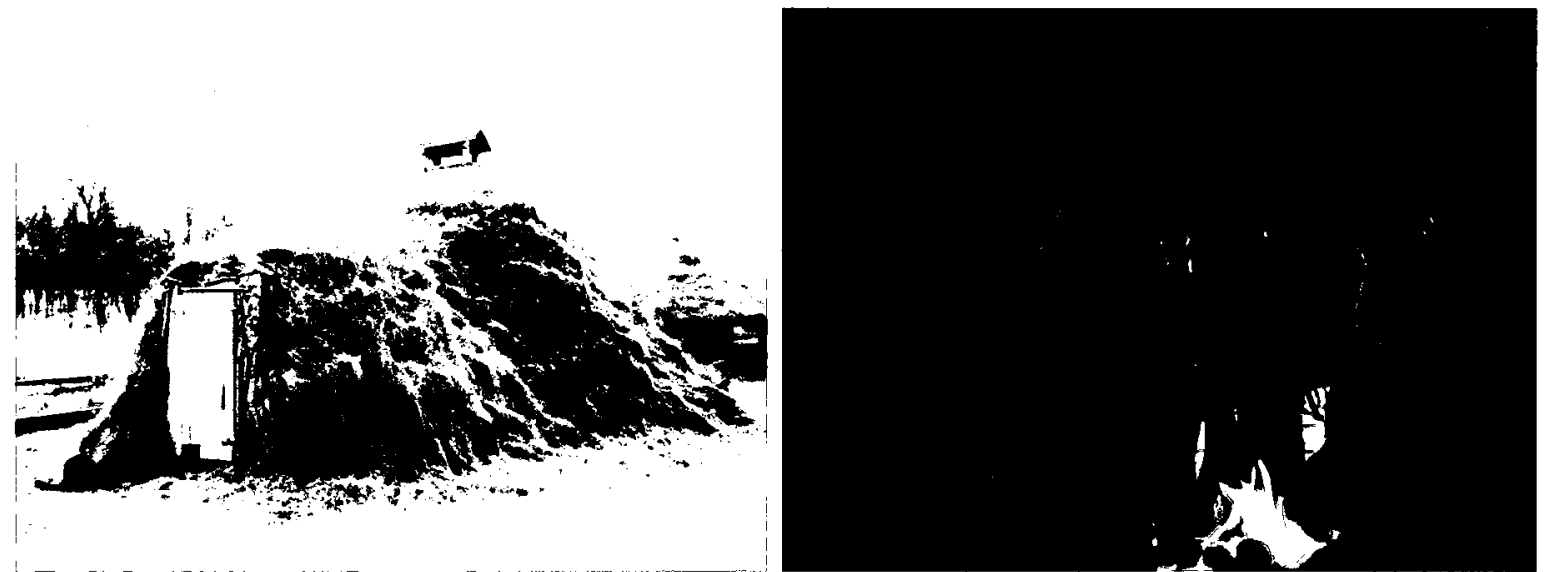

Fig. 13: A traditional Sámi darfegoahti (turf hut), part of a reconstructed Sámi village in Lakselvbukt, Norway 


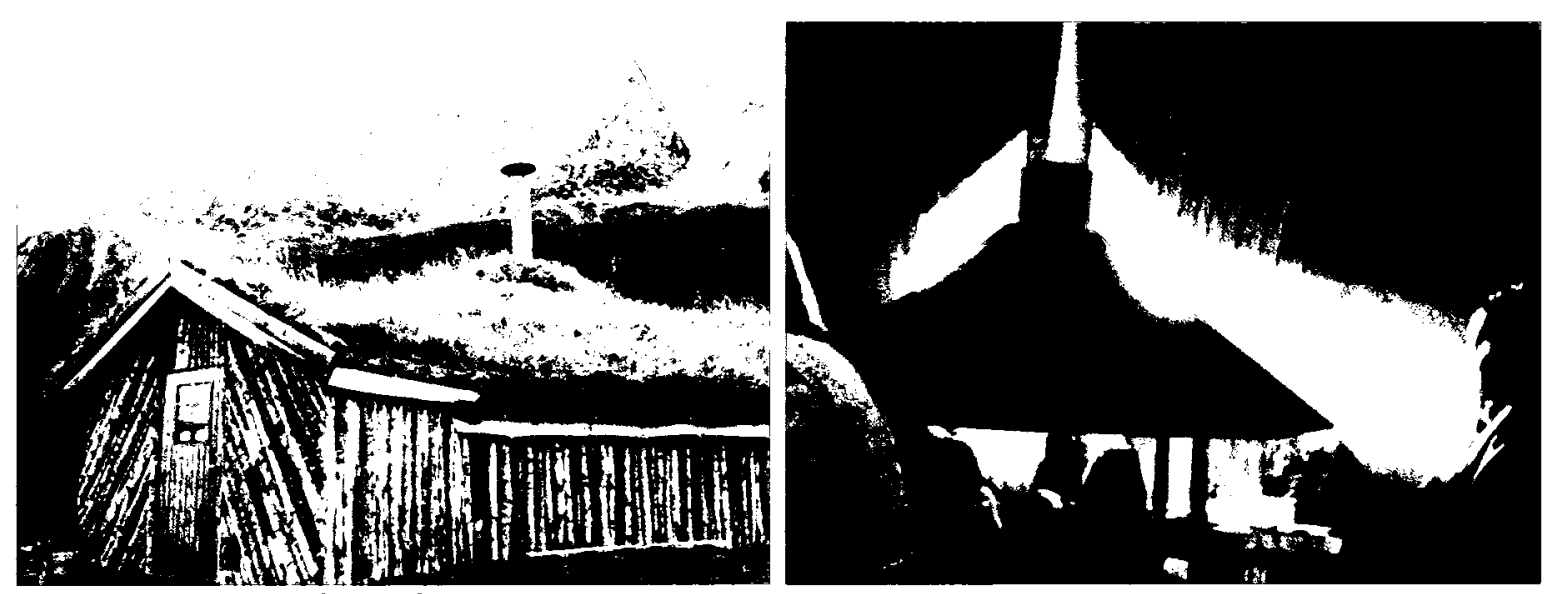

Fig. 14: A Sámi log cabin and interior

In describing the health of Sámi people, reflections on lifestyle and house form directly influenced diagnosis by local health care observers of southern origin. The people who lived on the coast and subsisted themselves on fishing and farming tended to live in earthen huts. Prevalent racism tinged the observations of the Norwegian doctors in the Sami districts in the late nineteenth and early twentieth centuries; they criticised the living conditions as unsuitable shelter for human beings. ${ }^{63}$ The log cabins of inland settled Sámi were considered superior to those of the coastal people and also of the tents and earthen huts of the nomadic reindeer herding Sámi population. The sanitation was considered best in the log cabins, and despicable in the tents and earth huts. These housing forms were considered substandard - the ones that more closely resembled that of the colonising culture were clearly favoured by the doctors. The Sámi themselves didn't necessarily always agree, since the concepts of what constitutes a good life and good health are culturally determined. ${ }^{64}$ This is a similar thread to the attitudes of traditional Inuit housing, which was considered squalid; especially the hybrid forms that started to emerge with the influx of different materials such as plywood, canvas and paper. ${ }^{65}$ 
Cross-cultural pedagogy has since been developed in a comprehensive way in Norway. It had been realised that not only the Norwegian caregivers had to be trained in Sámi cultural knowledge and skills, but that the Sámi practitioners also required an analytical approach to their own ethnicity and culture. ${ }^{66}$ This nascent concept must develop with the nurture that is also cross-disciplinary. Politicians, persons in other professions and non-indigenous colleagues must all work towards a similar goal.

The Sámi appear to find it easier to receive their education in their own part of the country than away, as enrolment in local schools is high where spots in distant schools are left unfilled. It is a very good possibility that keeping Inuit students in their region to learn would likewise ensure more people interested would opt to go. This is crucial in developing knowledge and creative based professions in the region to complement the development of trades such as carpentry and craft-making. This is certainly what the elders had in mind when envisioning a healing centre in Cape Dorset. There is great emphasis on healing through cultural education. An awareness of the wealth of and possibilities within a person's own language (oral, written, architectural and otherwise) makes him or her proud, and this awareness, therefore, contributes to creating a positive image of the language and the people who use it. ${ }^{67}$ The building has great symbolic value for the community, but serves as a necessary organ that revitalises the community. It is both prophylactic and curative. 


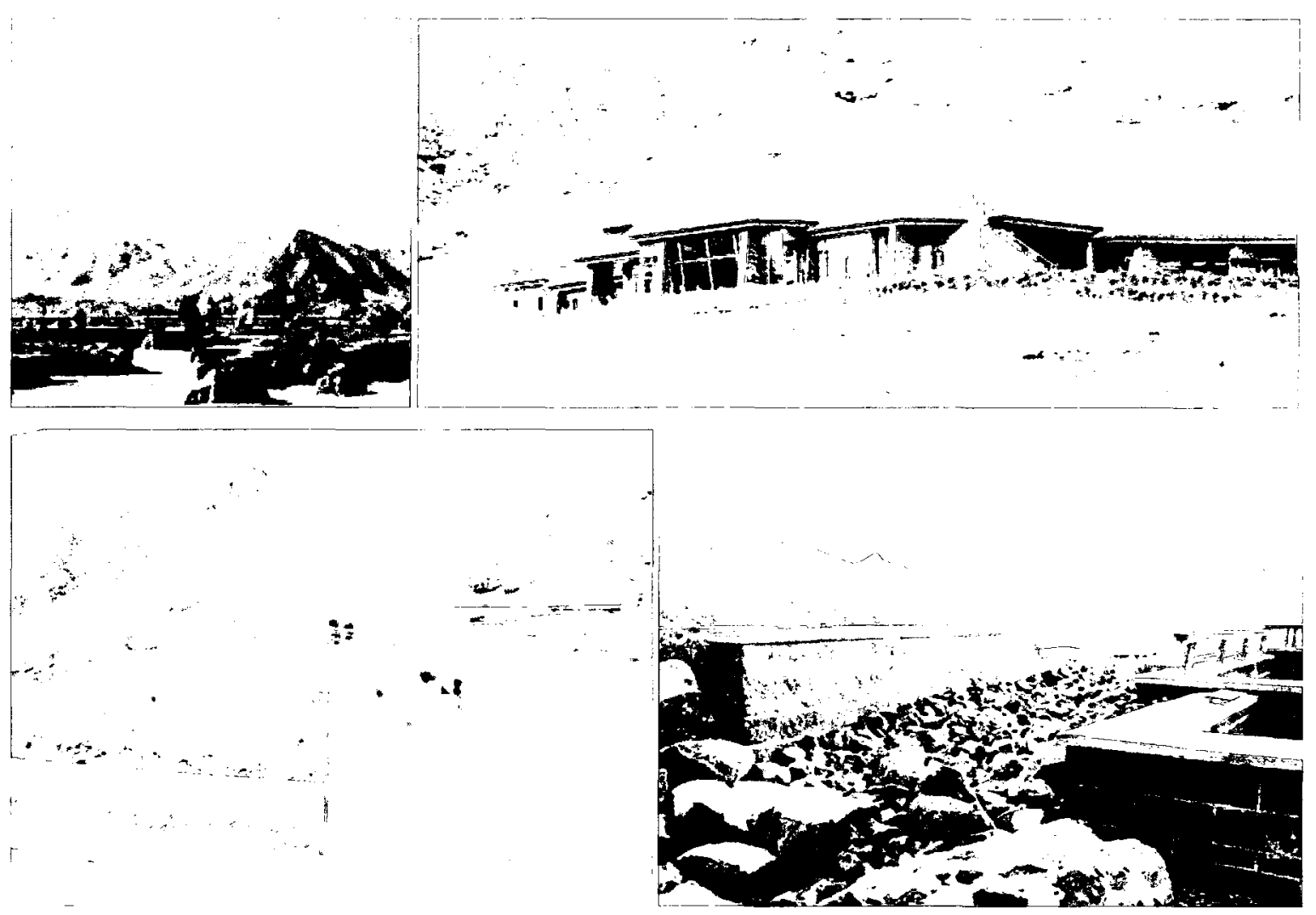

(Clockwise from top left) Fig. 15: View from the Roof Terrace of Denali, Fig. 16: The Eielson Visitor's Center, Fig. 17: Roof view of the Alaska Range showing stone drainage, Fig. 18: Green roof blending in with the natural environment.

After hours driving down a lone, winding dirt road, the dusty green bus drops visitors off at the scheduled stop for Eielson Visitor Centre. However, it is almost indiscernible where the building actually is. We have been standing on manicured verdant platforms that form the roof of the building. This newly constructed visitor centre is the first Platinum LEED building in Alaska. RIM Architects was confronted with a daunting task of building in a remote location akin to our project in Cape Dorset, with some variations. The nearest landfill was 100 miles away, and furthermore, the site was in the middle of a protected national park. The remote site created 
logistical obstacles, and the resolution that included building with excavated stone complemented potential inspiration for building in Cape Dorset. The strategy of setting the building in harmony within the folds of the mountainous landscape corresponds to place-fitting principals of this research. The centre existing at the site was dismantled and re-used continuing the cradle to cradle ethos of responsible design.

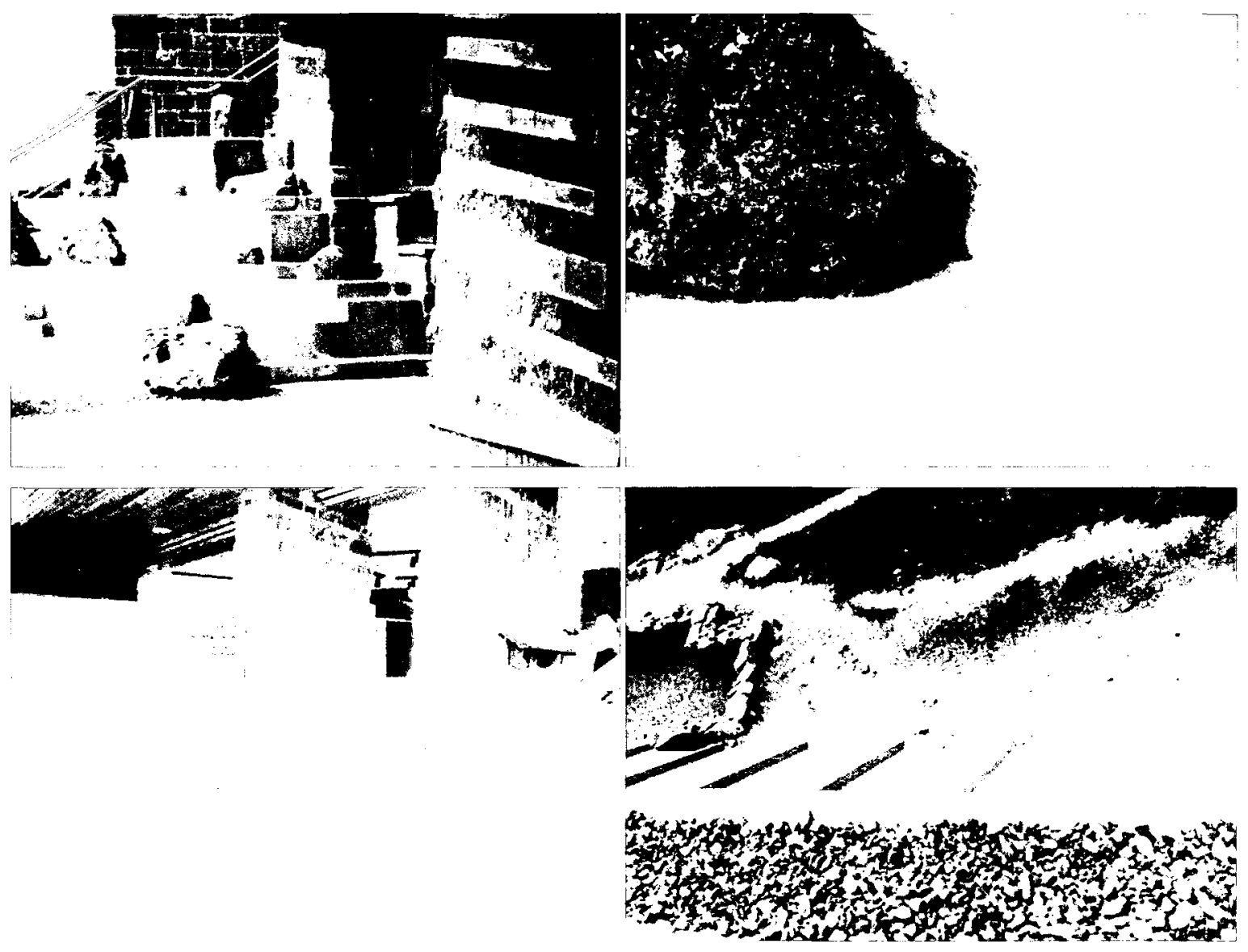

Fig. 19: (clockwise from top left) Exterior staircase leading to the roof terrace; Detail of rock meeting concrete, Boulders imbedded in the floor; Pebbles in the gutter for drainage.

The material of the site has been given prominence in all dimensions of the building. Stone from the site has been reintegrated into the building in raw form, given prominent placement for 
seating and steps (Fig 18). Massive stone supports on the interior in similar composition to the exterior supports extends the exterior to the inside. Ample fenestration provides wide vistas of the Alaska Range, and particularly the magnificent Denali (Mount McKinley), and further connects visitors to the landscape. This interrelationship between materials and space provides a sense of place.

\section{Temppeliaukio Kirkko, Helsinki, Finland}

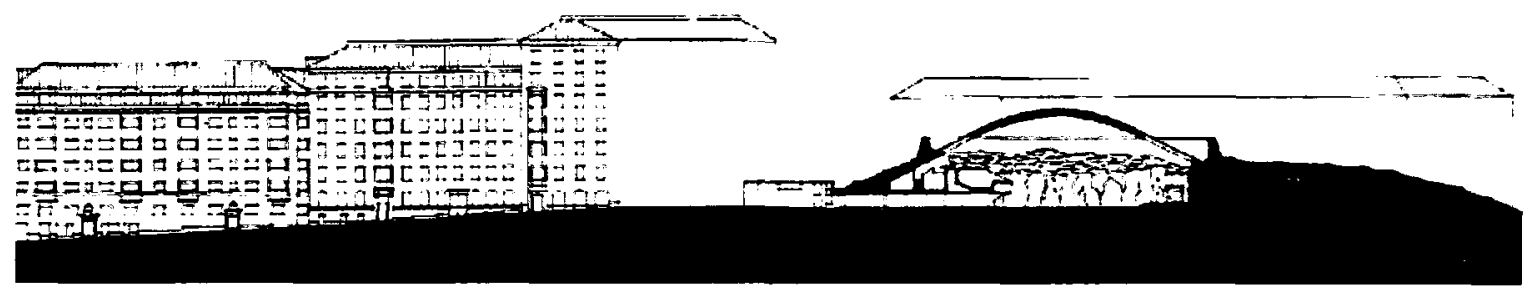

Fig. 20: Section through Temppeliaukion Kirkko

Carved out from a 40-foot granite outcrop in the middle of a city square in Helsinki, Temppeliaukion Kirkko unabashedly focuses on the rock. Commonly known in English as Church of the Rocks or the Rock Church, Temppeliaukion was built in $1969 .{ }^{68}$ Unlike the remote visitor centre in Alaska, the site in bustling central Helsinki had easier access to building resources. Yet, here too the architects Timo and Tuomo Suomalainen decided to use materials available from the site in the building's construction. It was through intuition upon first visiting the site that in order to preserve the rock, as requested in the competition, they must treat the architecture and the material as one and the same. Everything built at the site would be adjusted to accompany the character of the rock. ${ }^{69}$ Their winning design in a competition in 1961 was 
the second winning design that focused on the knoll, as the design from the earlier competition was cancelled at the start of World War II and it was only through great endeavour that the results from the second competition were completed. There was debate about the necessity of the building as sacral spaces were becoming less socially important. Original programmatic elements of the church were limited and spaces were diminished. The cost of building the church was equivalent to that an average sized school building, though it was often viewed as a major financial investment by local media outlets. ${ }^{70}$ The church is now one of the most visited sites in Helsinki. ${ }^{71}$ The excavated rock was found to be technically, aesthetically and acoustically unsurpassable, as well as embodying the spiritual relationship of sacred space with nature and stability. ${ }^{72}$

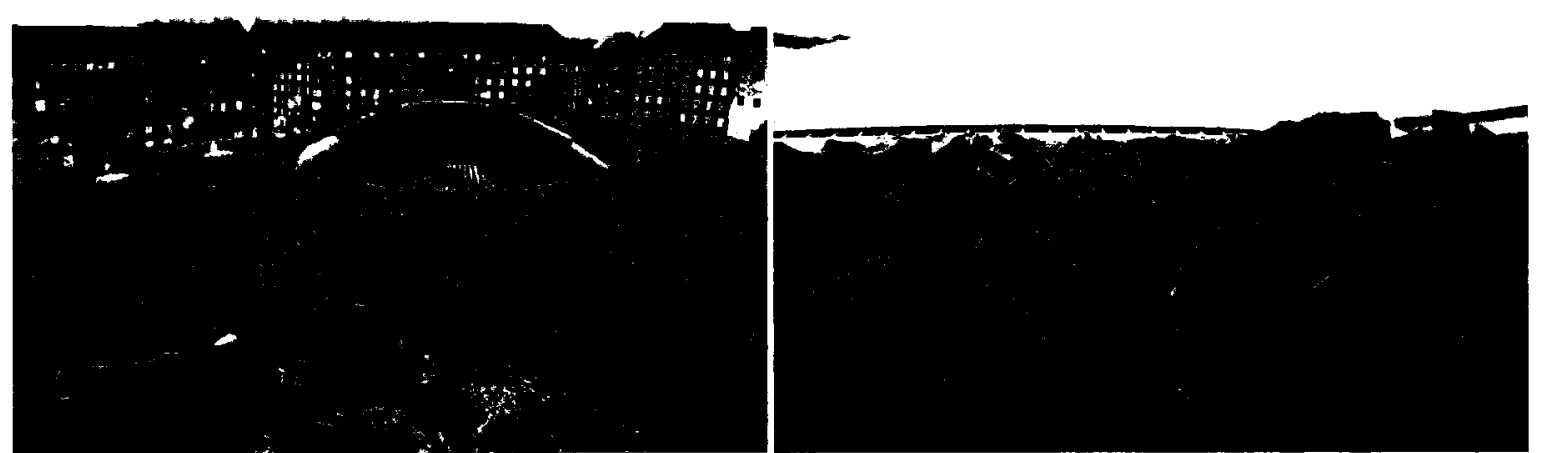

(left to right) Fig. 21: Temppeliaukion Kirkko is excavated from a granite knoll in the middle of a Helsinki city square. Fig. 22: The excavated stone is re-used in the structure.

The Suomalainen brothers focused their design mainly upon the granite rock which provides the foundation, walls and roof of the building, exception given to clerestory fenestration and a 
copper dome. The excavated walls were left jagged and raw, thereby creating a superior acoustic atmosphere. The technique also parallels indigenous building procedures and ideas.
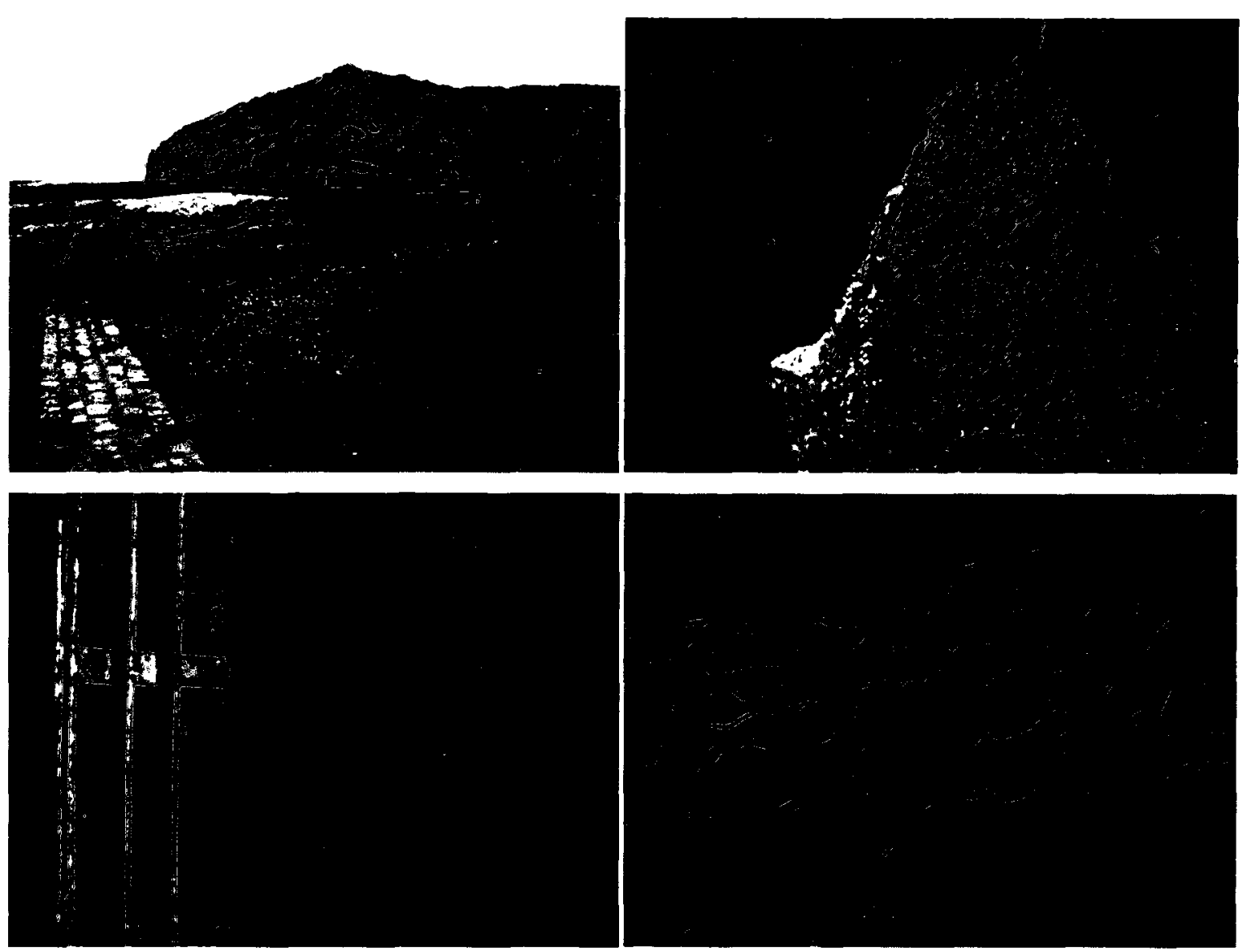

Fig. 23: (clockwise from top right) View of the roof; Joint detail; Material details; Drainage detail

The smoothness and precision of concrete and the warm tone of copper juxtaposed with the bedrock and quarried stone give the space a breathable character. ${ }^{73}$ The connection to nature is instilled with austere stone and the invigorating water dripping from the walls. With excavated material re-used in building construction, the Temppeliaukio Kirkko attests to the power of the site and material to create inspirational space. 
The design of the building, in contrast to the Cape Dorset cultural healing centre, did not involve the input of community members, as it was determined by a competition. It was also marred by controversy, as true authorship to the sacral iconic tenets of the rock church was falsely presumed to be attributed to another architect's earlier proposal for the initial competition. This is not to say that competitions are not the best or the worst way to design. The architects are from Finland, have trained regionally and are part of the Finnish zeitgeist. However, in Cape Dorset there are no local architects. Traditionally each person was his or her own architect. Co-design is an integral step in bringing architectural design back into the community. Ideally, architecture would come from within the community, and may be influenced by outside factors at the designer's creative discretion, as is observed in the local carving and printing industry. The design process for this cultural healing centre was suitable in such a manner. 
Notes

${ }^{63}$ Siy Kvernmo. "Developing the Sami Health Services - A Medical and Cultural Challenge," Sami Culture in a New Era: The Norwegian Sami Experience. Harald Gaski ed. (Seattle: University of Washington Press, 1997) 129.

${ }^{64}$ Kvernmo, 134.

${ }^{65}$ Peter Dawson. 'Unfriendly Architecture: Using Observations of Inuit Spatial Behaviour to Design Culturally sustaining Houses in Arctic Canada'. Housing Studies, Vol. 23, No. 1, 111-128, January 2008. 112.

${ }^{66}$ Kvernmo, 136.

${ }^{67}$ Harald Gaski, "Introduction: Sami Culture in the New Era,".Sami Culture in a New Era: The Norwegian Sami Experience. Harald Gaski ed. (Seattle: University of Washington Press, 1997)15.

${ }^{68}$ Maila Mehtälä. Rectification to the Design History of the Temppeliaukio Church. 12.11.2007. 2-4 <http://www.temppeliaukio.fi/>

${ }^{69}$ Mehtälä, 2.

${ }^{70}$ Mehtälä, 4 .

${ }^{71}$ Roger Connah. Grace and Architecture. (Tampere, Finland: Rakennustieto Oy, 1998) 5

${ }^{72}$ Mehtälä, 4.

${ }^{73}$ Jetsonen, Sirkkaliisa. Sacral Space: Modern Finnish Churches. (Tempere: Rakennustieto Oy, 2003) 


\section{Design}

The designs presented are meant to encourage Inuit and Southerners alike to consider the potential possibilities that exist in architecture for the North. These may be found to be a catalyst to new solutions from within the community.

\section{Initial Concept}

The first meeting with local community Elders, representing themselves as well as the Healing Team and Community Justice Team, began in June, 2007. It was ascertained at this early meeting that there was a specific program in mind to be built in the community - a healing centre. Healing was implied at all levels, from individual treatment and counselling, to conflict resolution between individuals, at a greater community level to combat and cope with suicide, alcohol abuse, and other social maladies, as well as to emphasise environmental stewardship and mend the relationship between people and nature.

A design for a cultural healing centre was prepared before a second consultation with the local community members to show that a design initiative was taken beforehand that would be able to be critiqued and discussed. Based on historical research of traditional vernacular spatial concepts and building techniques, a plan was presented during the second meeting that was met with encouragement and appreciation. It was presented before the healing team at the beginning of the workshop. 


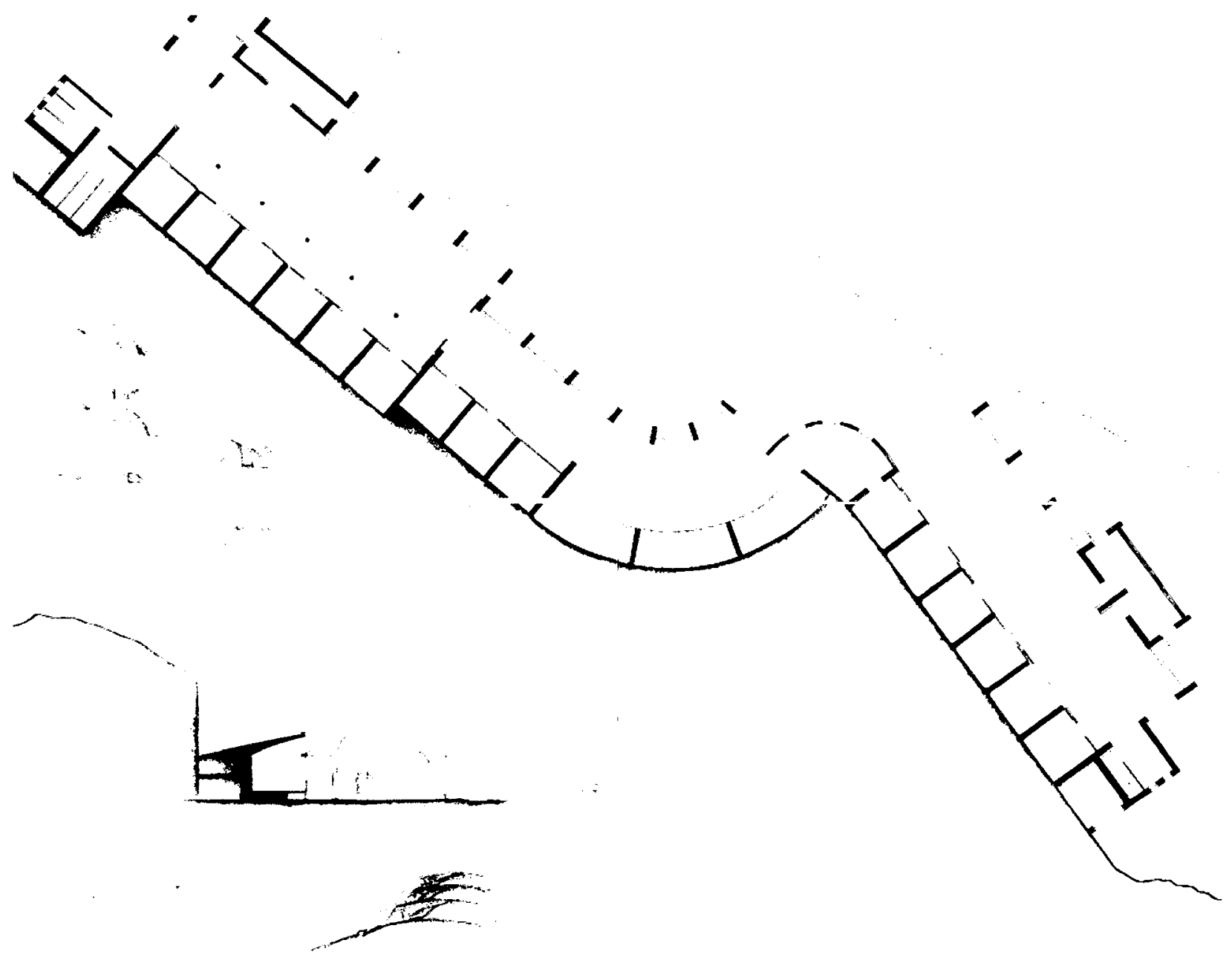

Fig. 24: Preliminary Plan and Section with sketches

The preliminary design interpreted traditional architectural language, particularly of the stone and turf hut. As traditional meeting places were simply larger versions of the residential domicile, the spatial organisation of the home was mimicked. Large, shared spaces would have ancillary spaces directly adjacent and accessible. These spaces may be shut with sliding panels to create privacy if desired. As demand for space grew, the building could 'grow' along the ridge. This growth would actually be hewn from the ridge itself, and the excavated stone would be reused as finishing material, though cut using modern grinders, laser cutters and the like to 
achieve a modern finished aesthetic. It was a well received notion, and the Elder's were eager to begin a collaborative design workshop. Though there was potential for the preliminary design to influence participant's work, the results proved otherwise.

\section{Local Designs}

In an effort to draw out local expressions of what such a place is, a workshop was organised that encouraged community members to envision their own cultural healing centre. Participants, mainly small groups of Elders and women, drew a series of plans and elevations that show what they considered necessary in the centre. The enthusiasm to participate in a design workshop was strong among the healing team of Cape Dorset and garnered support among other community members. The drawings yielded in the workshops were intriguing and certain characteristics showed among drawings from different groups.

Drawings produced by locals in the following charrette produced different spatial organisation and program than the initial concept. Another workshop was held to translate the Inuktitut text, and discuss the drawings more thoroughly. It was at this point that the project began to be called a cultural centre, as it was soon realised that the re-invigoration of traditional Inuit culture was a means of healing, of instilling identity and that this would increase the strength and well being of individuals and of the community as a whole. 
The Elders drew mainly plans and some elevations in traditional manners with modern programming. The qammaq form was clearly favoured, which alludes to the spatial organisation of traditional Inuit space. The Elders astutely considered modern infrastructural methods that affected the designs. These include spaces for mechanical and heating equipment, water storage and heating, septic repository, and custodial areas. Washrooms are divided by gender. There are vestibules for entry, and there are two entrances in every design. Some Elders expanded the program by dividing similar programming such as meeting and workspaces into both masculine and feminine realms. Traditional programming is also maintained, as expected in a building that is to focus on cultural healing. Cold and cool areas of storage are included near entrances, and heated storage is also implemented. All spaces have immediate access to a central meeting place, or katimavik.

The participating youth had elements that favoured literal iconic cultural relevance as well as traditional building forms. Kayaks, ulus and men's hunting knives were drawn directly on the facades or in the sections. Though not a scientific study, the drawings suggest that there may be differences in perception among generations, which may be influenced by contemporary forms of representation. 

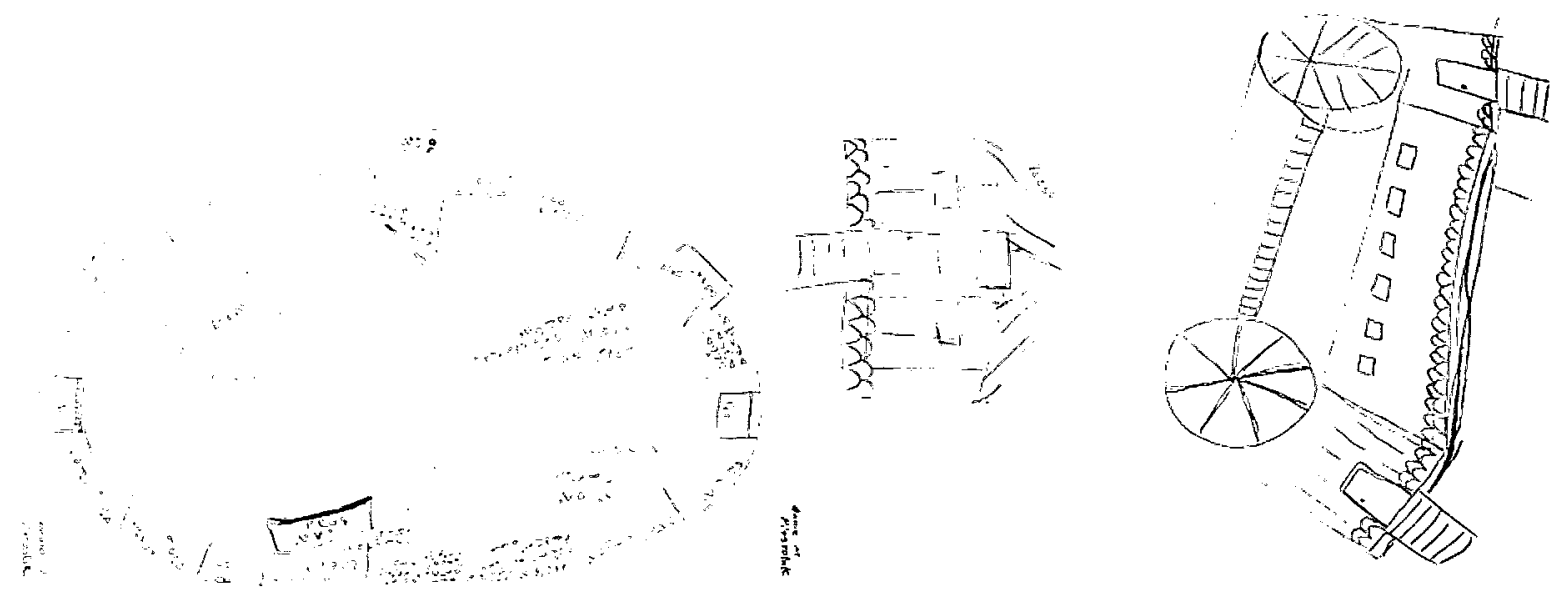

Fig. 25: Annie Pitseolak's plan and elevations for a Cultural Healing Centre.

Annie Pitseolak envisioned a relatively large katimavik with half being divisible with moving walls. All rooms radiate from this central meeting area as well, with mechanical and washroom spaces in the intermediate space between katimavik halves. Entry is at one end of the elliptical plan, as well as from the side of the main space. Her programmatic desires were the most extensive of the participants, with considerations of a variety of spaces, but with particular emphasis on differentiating between elder and youth spaces, and between men's and women's spaces. This differentiation was to allow for the youth to be boisterous or loud and still provide sanctuary or relative quiet in their activities.

Pitseolak's elevations are based on the traditional qammaq with modern adaptations. The large circular elements at the ends of the roof are windows. There are stones at the base acting as a foundation in tandem with the contemporary raised structure as there are entries at either end, and the staircases that have become ubiquitous in arctic communities descend from them. The 
buildings in Cape Dorset are all raised a few metres to prevent the building from melting the permafrost as well as to allow for snow accumulation.

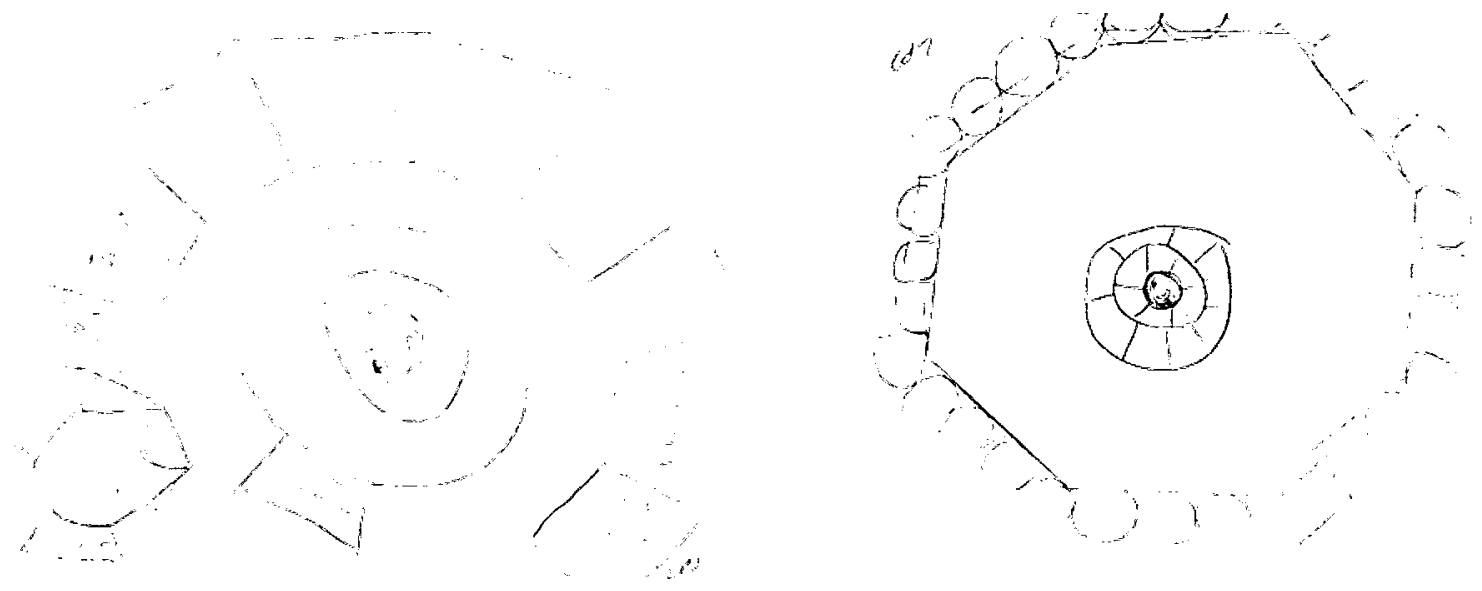

Fig. 26: Qauna Makkigak's Cultural Healing Centre plan and roof plan

The design by Qauna Makkigak is also focused around a central katimavik, but in her version it rests at a lower level than the surrounding programmatic space. Cold storage near the entrance follows the centric plan in miniature. The roof plan shows a window over the katimavik modeled after the snow house. The walls reuse barrels for structure. This was mentioned as a way of reusing otherwise discarded materials. The metal dump and garbage heap in Cape Dorset continues to accumulate, and no waste brought into the community ever leaves. Makkigak's reaction to the present situation shows the need for all things to be considered long-term, and strives to find a use for existing excess materials in the community currently left to waste. 
sensut $\angle A, 2$

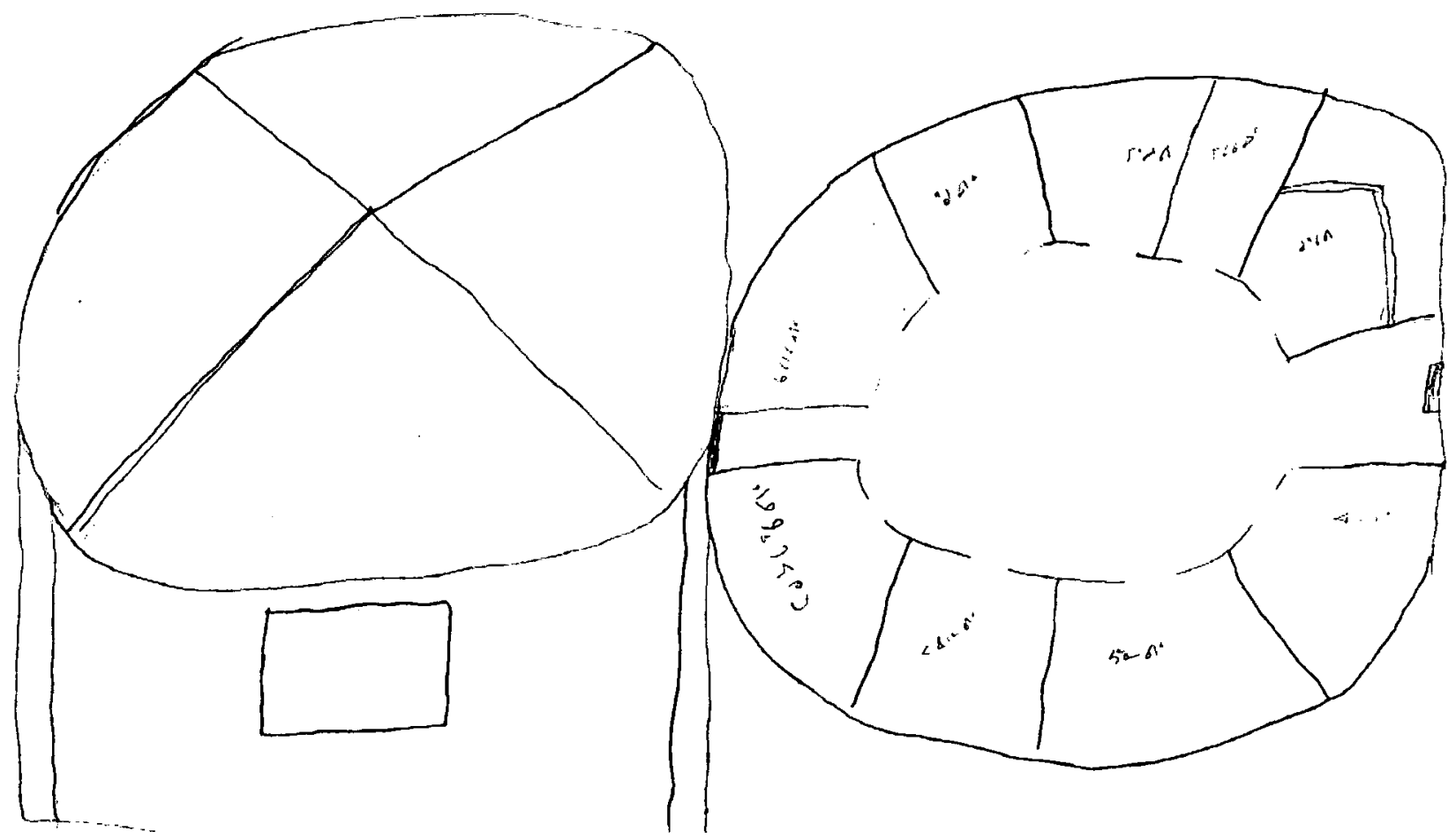

Fig. 27: Aranasuk Laisa's plan and elevation

Laisa's depiction shows a qammaq design with an interior again reflecting the focus of a main central katimavik with workshop spaces, kitchen and other elements radiating directly out. There are two entrances at either end. 

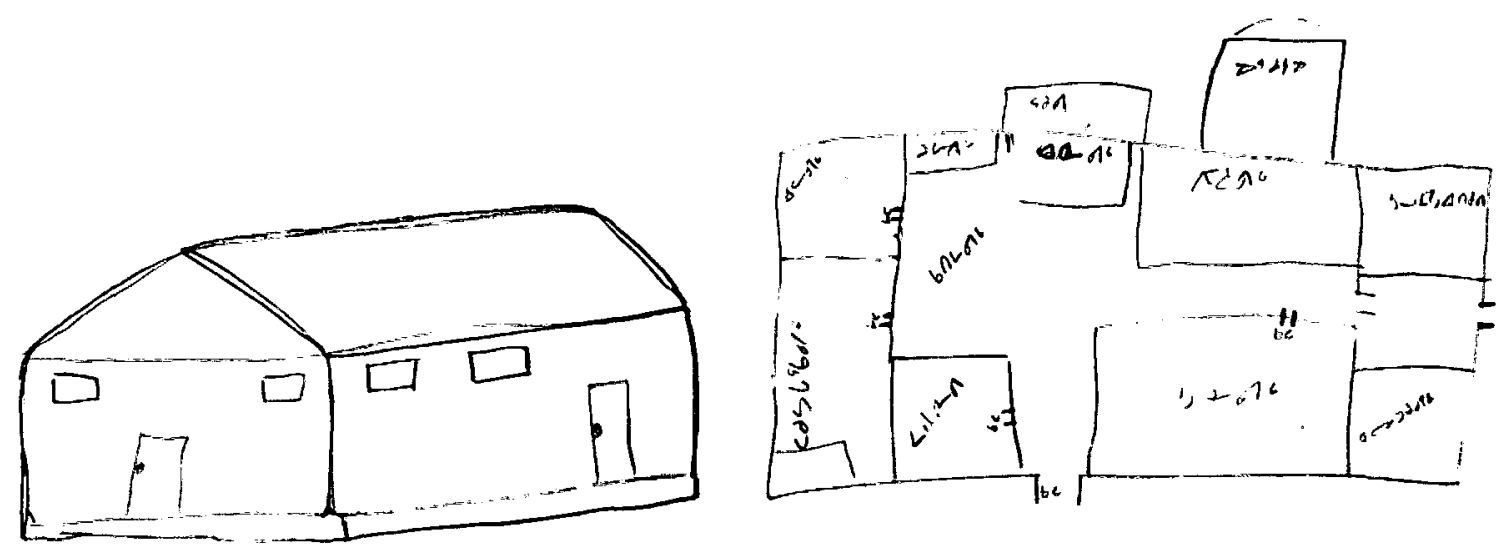

Fig. 28: Mayureak Quvainaqtuliaq perspective and plan

Quvainaqtuliaq's plan is more orthogonal than the rest, although the edges of the perspective are tapered. The space is organised around a central katimavik. The washroom and septic are shown outside the main envelope of the building, and the cold storage areas are located in a cooler vestibule at one of the entrances. The orthogonal dimensions do not necessarily contradict more organic forms of traditional buildings, and the spatial concept can loosely be seen in them, though they are expanded here with added modern programming and needs.

The workshop with local youth produced a different set of drawings that revealed awareness and connection to the past, but drawn in a different manner. Some were similarly drawn with a mix of plan, perspective and section all in one drawing. The buildings almost all resembled traditional building forms, but literal iconography was uniformly applied to the buildings. This was absent in the drawings by the Elders, and is a potential difference in perspective that could further be examined. 


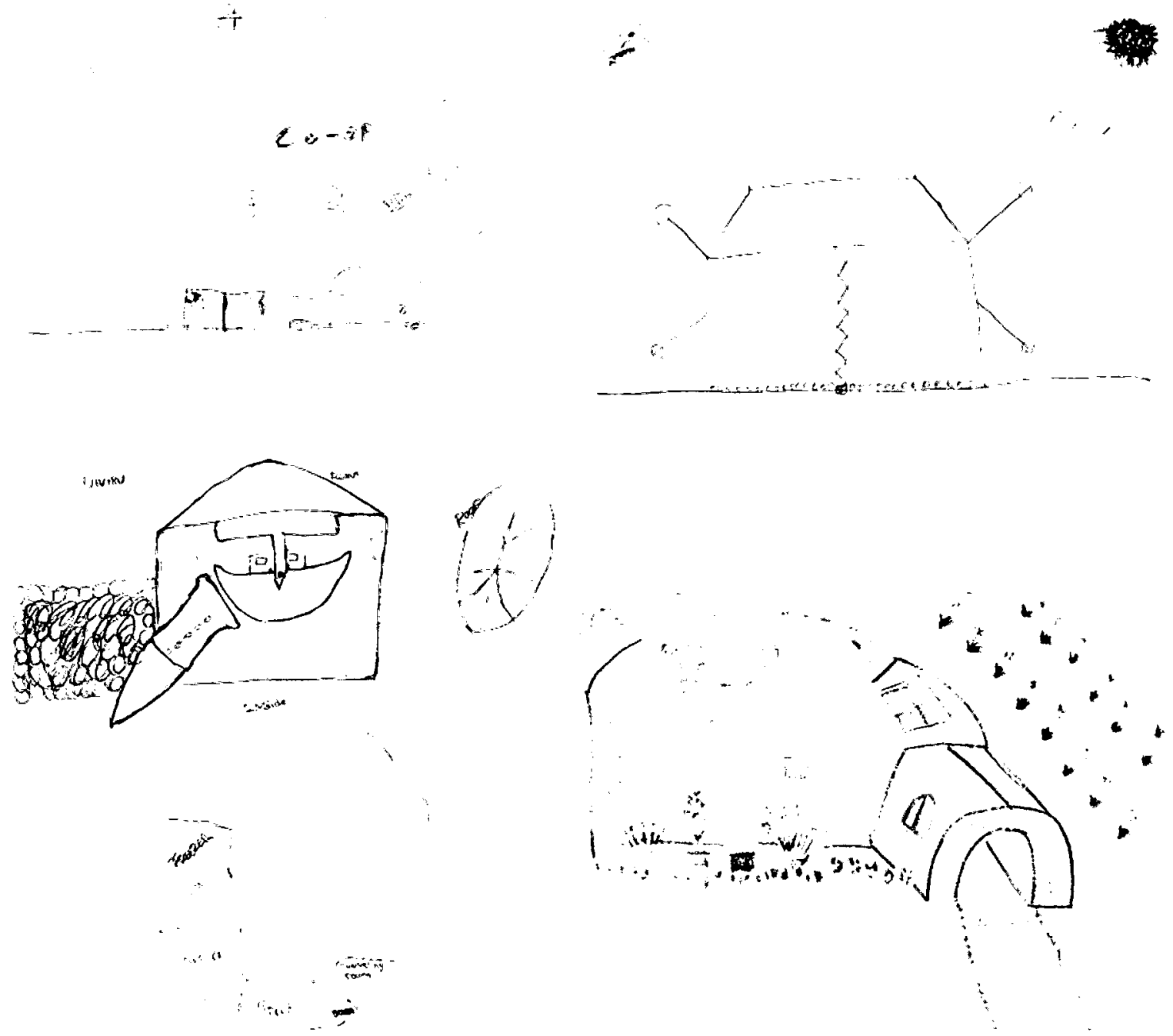

(clockwise) Fig. 29: Mialia Oqutaq's design of a mobile centre, Fig. 30: Oqutaq's design based on a canvas tent, Fig. 31: Design by Uiviru Tapaungai, Fig. 32: Design by Silaqqi Quvianaqtuliaq

Mialia Oqutaq was a young participant who had included mobility into one of her drawings, a cultural centre on wheels. Other drawings depicted traditional temporary dwellings outright. Uiviru Tapaungai drew a plan similar in organisation to the Elder's designs, but different programmatic space does not continue all the way around the central katimavik. A hunting knive and $u l u$ are depicted quite pronouncedly on the façade. Silaqqi Quvianaqtuliaq’s healing centre 
maintained a traditional form, but used contemporary fenestration. An $u l u$ and hunting knife are also shown on the building beside its sign.

There are a few programmatic elements that are common throughout the drawings: a central meeting space, or katimavik, a museum, a sewing area, a daycare, an office, a kitchen, washrooms, mechanical spaces, and cool and warm storage areas. Various other programmatic elements are found in only one or two drawings: a coffee room, workshop, place to clean skin, smaller katimaviks specifically designated (young males, young females, Elder males, and Elder females), water storage, a place to learn to make tents, a recreation area, a massage area, janitor's closet, a porch or lobby, and a men's workshop.

These programmatic components are a fusion of traditional activities and contemporary ones and reflect the fluidity of culture. The meanings of each of these words - museum, daycare, and workshop - can also be deconstructed or interpreted in a number of ways. A museum, for example, may be simply a collection of relics on display. Many Indigenous museums, conversely, incorporate a diverse program that they may more appropriately be called cultural centres. They would still contain artefacts, as objects have held significant power as mnemonic devices for cultures of strong oral tradition, they are tools to continue. ${ }^{74}$ These museums may contain libraries that contain local literature and interest. Elders may also be invited to transmit traditional lore and language to children. ${ }^{75}$ Training may be offered in dance and music, sometimes in cooking, and in the traditional use of plants. The community may use them for 
meetings or celebrations, perhaps in an effort to be closer to cultural artefacts, and potentially some that are forbidden to tourists. ${ }^{76}$ According to the Canadian Museum Association, the institutions engage their visitors, foster deeper understanding and promote the enjoyment and sharing of authentic cultural and natural heritage. They acquire, preserve, research, interpret and exhibit the tangible and intangible evidence of society and nature. As educational institutions, they provide a physical forum for critical inquiry and investigation. ${ }^{77}$ The International Council of Museums further extrapolates that the underlying objective is to achieve higher levels of excellence in all spheres of life by engaging the entire population and drawing on the full diversity of local culture, heritage, experience and knowledge. ${ }^{78}$ Museums have increasingly become forums for the promotion of community relations and peace. In addressing the problems of the world created due to inadequate cross cultural understanding, historical fears and ethnic tensions, they are increasingly connecting with the important role that they can play in the promotion of cultural understanding through negotiated activities driven by community relations strategies. ${ }^{79}$

According to the expressed intents of the healing team, it is exactly these 'museum' activities that they hope would transpire in their cultural healing centre, thereby combining descriptors of requested components such as museum, library, resource centre, healing centre, community justice centre and cultural centre into one cultural healing centre.

Beyond the noble programmatic expectations of the centre, a spatial context is also revealed. In all forthcoming drawings, the central katimavik has all other programmatic elements radiated 
outwards from it, and immediately so. There is always a direct link between any given function and the centre space, with exception to water and septic storage. This reflects the dynamics of the traditional snow house, which Edmund Carpenter describes as an "aural, acoustic, non-linear bubble of space" ${ }^{80}$ :

\footnotetext{
'Visually and acoustically the igloo is 'open', a labyrinth alive with the movements of crowded people. No flat static walls arrest the ear or eye, but voices and laughter come from several directions and the eye can glance through here, past there, catching glimpses of nearly everyone. ${ }^{\text {'1 }}$
}

Literal depictions of shelves, people, barrels, stones, and the like were falsely interpreted in initial deciphering of the drawings, and only revealed during discussions in consequent workshops. Scale, proportion and perspective were all imbedded with a distinct Inuit essence. These distinctions in sign and signifier contribute to the hybridization process of developing crosscultural designs and impact final outcomes.

After considerations and analyses of the Elders' and youths' drawings, a second plan was created. It was two storeys, with a top level designated to the youth. The Elders had space on the first level around the main katimavik. Gender differentiation was also given, with healing spaces for the men's and women's healing team, as well as workshop areas for the production of ulus, hunting knives, carvings, kayaks and the cleaning, preparation and sewing of skins. A workshop was held to go over this design and it was determined that with so many programmatic spaces 
around the katimavik, some activities might disturb others, and that a little more differentiation of space might be needed. There was also concern raised about the use of stone. Though using stone was in keeping with tradition, scales of economy were raised as a consideration. Though this concern is valid, the use of excavated local stone must remain as an idea that has potential to overcome current economic limitations.
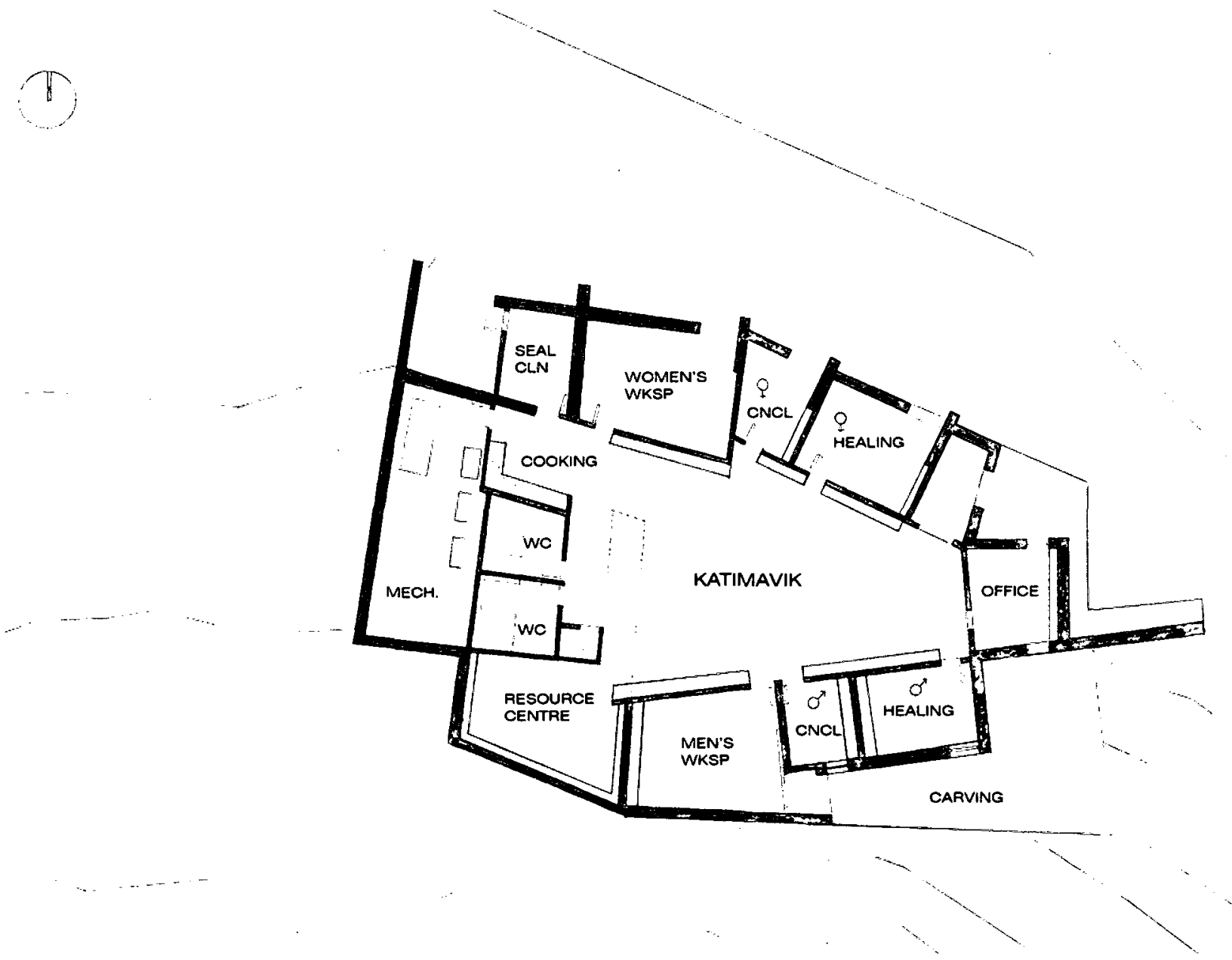

Fig. 33: Second iteration after initial workshops - first floor plan 


\section{Hybrid Designs}

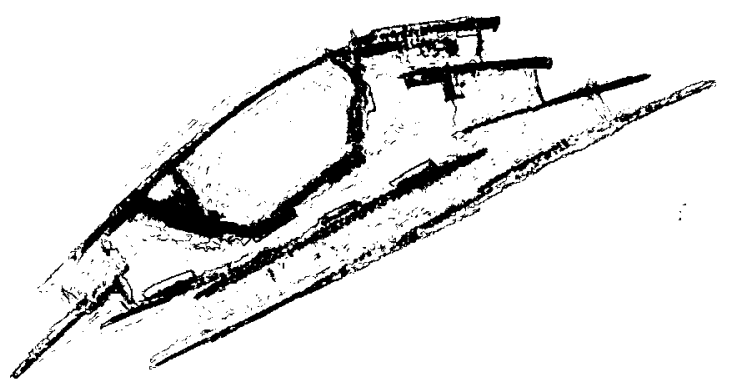

Subsequent designs taking community input into account resulted in a hybrid of new and old. Interest in design continues to gain momentum in the community as members request sending ideas and drawings via fax and e-mail for further design consideration.

Fig. 34: Parti of space removing the katimavik (light blue) from the centre

Given the ephemeral nature of the design process, the resultant architectural resolutions are also transitory in nature, and are a series of suggested details and forms that may be appropriate to Cape Dorset. They may be scrutinised and rejected or accepted by future decision makers in the community, but nonetheless are made available for consultation and as a testimony to the collaborative effort. It is hoped that the work acts as a catalyst to encourage local participation and dialogue in the field of architecture.

Spatial organisation took on a radial format with contemporary building construction techniques and materials. Materials are to be chosen that reflect the local context and are local where possible. This includes using the wide variety of locally quarried stones as interior finishing materials, but also cleaning and reusing materials that would otherwise be destined for 
the garbage heap. The project also makes the most out of valuable space considering the exorbitant costs associated with building in the North, but also provides potential cost-cutting innovations. The multi-media room / resource room is located at the north-western entrance to utilise the heat from electrical sources like computers. The seal skin storage area is located on the north-eastern to keep coolest. As the katimavik faces the northern side towards the water, the windows are relatively small, with skylights facing south.
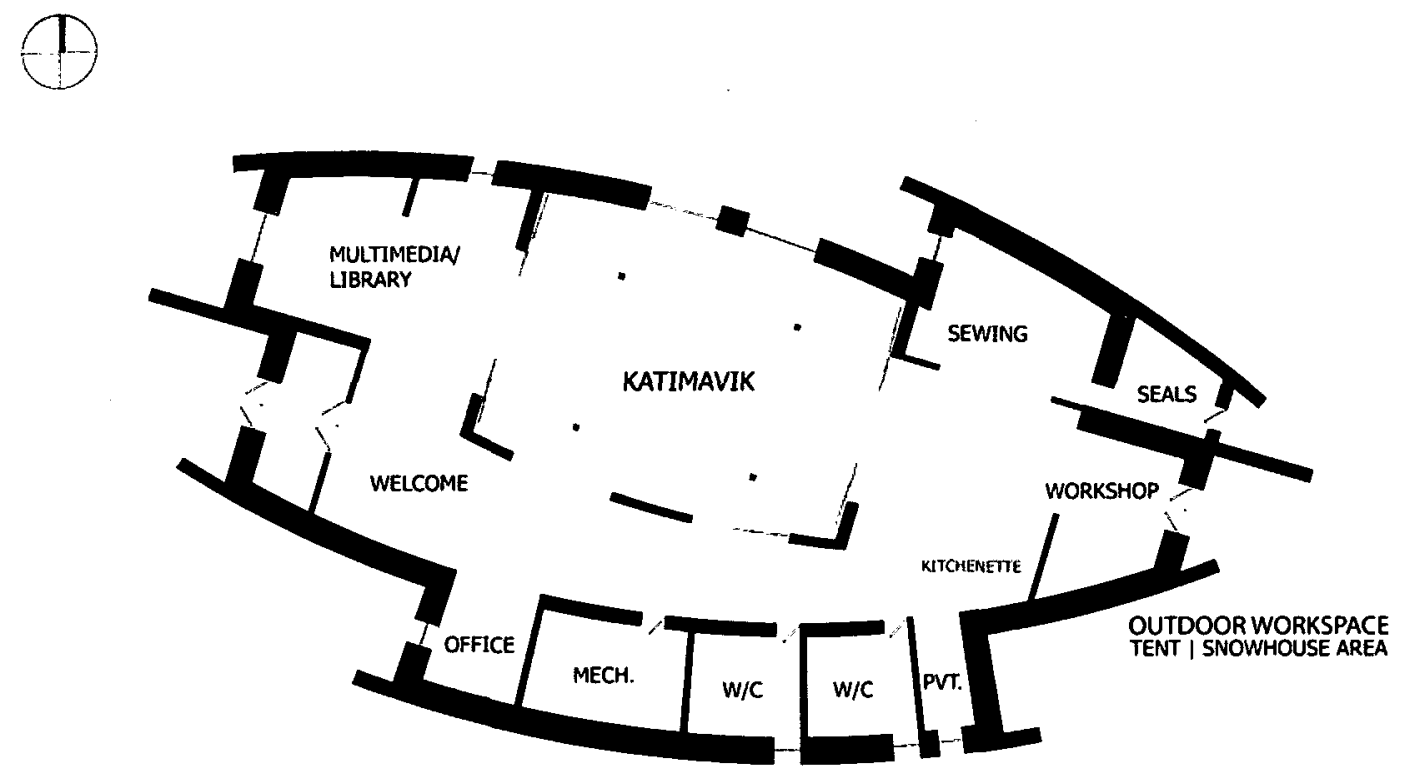

Fig. 35: Plan of Cultural Healing Centre 


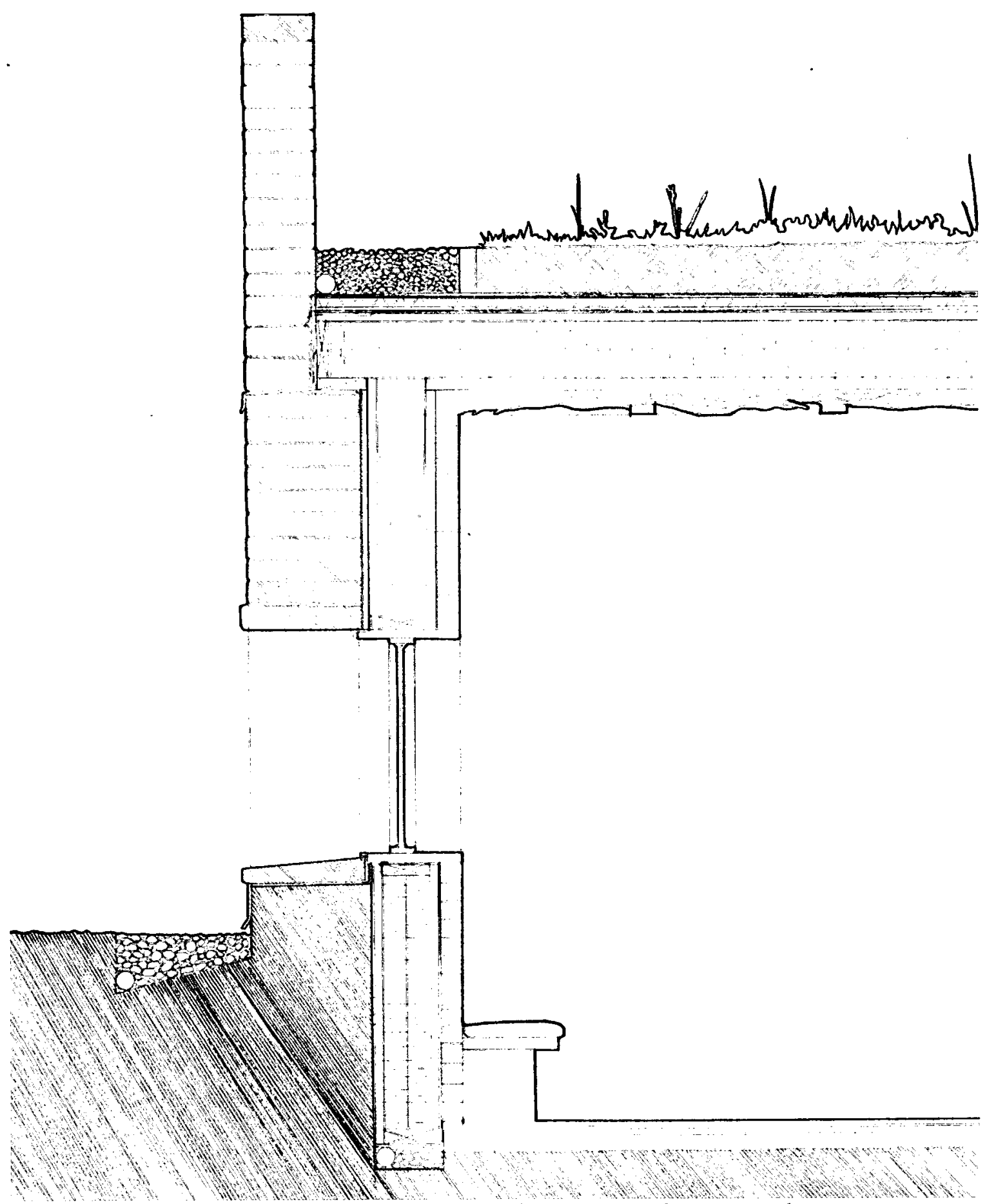

Fig. 36: Section Detail facing South with a flat green roof, and submerged approximately one metre. 
The form of the centre is derived from information brought together from the community designs. Most drawings indicated round or polygonal plans, as this has traditionally ensured the maximisation and efficiency of space for movement and heating. This is maintained in the hybrid design, thought the space is loftier. Though the increased space increases heating demand, it is mitigated by the thick stone supporting walls, green roof system, and potential sustainable energy supplies in the near future. The circles and oblongs are thought of concepts rather than rigid models, as people will naturally tend to congregate in a roughly circular pattern during meetings regardless of the shape of the room. ${ }^{82}$ That being said, allowing enough space for these congregations requires ample spaces in all directions outwards from the intended central focus and the abolishment of long, narrow constricting spaces. Further, there is no need to constrict people to rigidity when a building can be as 'free as a cloud'.

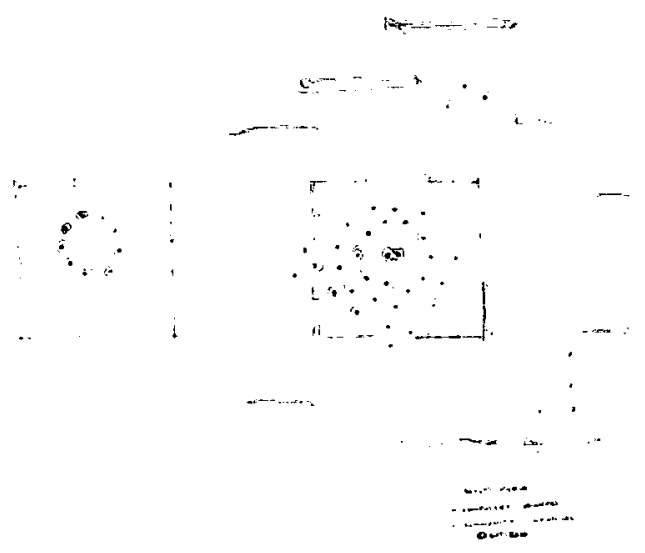

Fig. 37: Sketch showing that small groups may congregate within a set central katimavik, and with larger groups these may spill out into the other areas, with non-participants also able to use different spaces. 
The main katimavik becomes a versatile space that can be closed during private meetings while other people can continue to use the integrated peripheral spaces. These spaces can also be subdivided according to need or want of privacy with sliding panels.
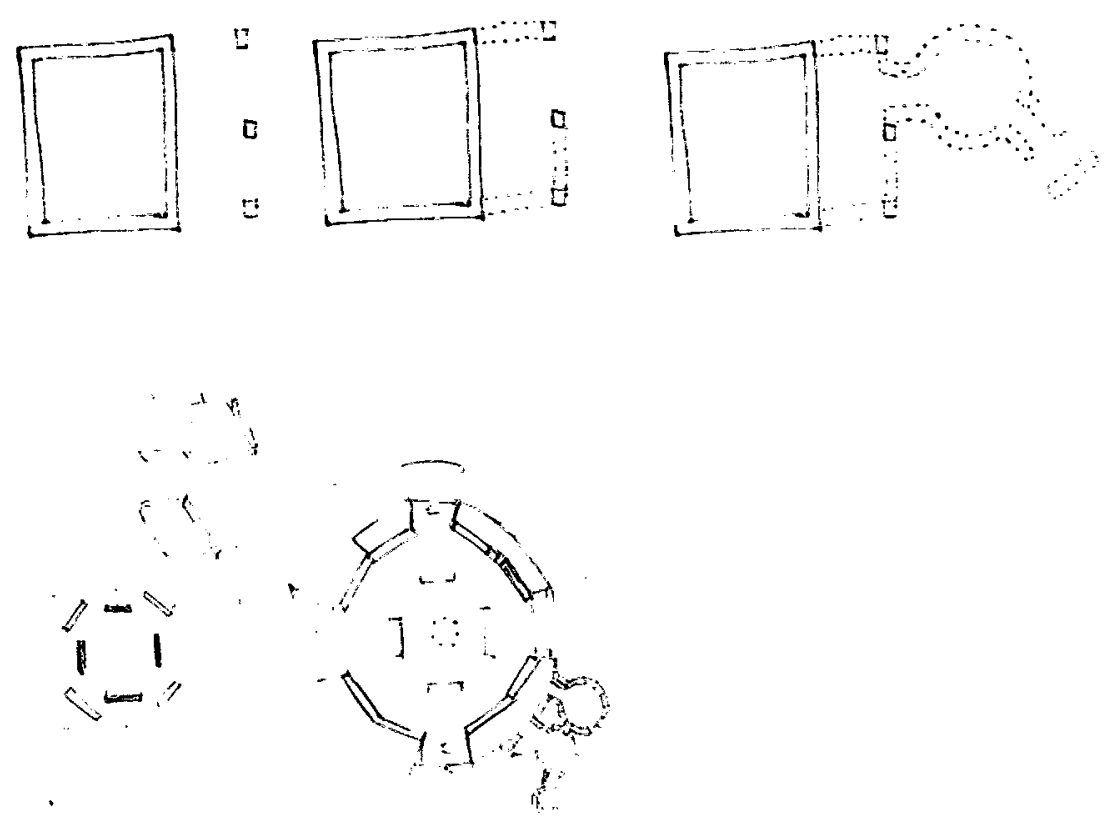

Fig. 38: Sketches showing potential seasonal metamorphosis

A framework for the building must be made to allow for alterations. These may come in more solid walls or, in the winter, snow or ice blocks that can be added to create more space, as well as integrating temporary traditional snow houses as a group activity. This will enable people who are unable to go out onto the land to nurture traditional cultural relationships with the land in the community.

The foundation of the centre could be excavated from the top of the granite ridge of the site. The space will therefore be sunken on the highest realm and elevated at the lowest. The excavated rock 
could be then reclaimed in the walls. Flooring would float above this excavated granite, with radiant floor heating as a possible integrated heat system. Structural stone walls of local granite would be made from the excavated foundation stone in a manner similar to that of the rock church. The roof may be flat, or curved. A curved roof opens up the space and follows a more traditional form, as well as is more structurally viable for snow loads. Whether the roof is wholly curved, flat or a combination of both, there must be at least a slight angle to ease drainage.

Some interior walls would be faced with soapstone, softer than the hard granite stone on the outside. Countertops would also be made of soapstone. White marble and serpentine may also face some walls, reflecting the diversity of available materials but also limiting the scale of quarrying that is already done at a community level for sculpting sources. As this stone would be quarried with the stone that the community normally acquires, it would similarly be seasonally transported into Cape Dorset. This structure would thus be built in accordance to the seasons and availability of sea ice, connecting to the past in a conceptual reference of time.

Materials such as insulation, vapour barriers and fenestration would have to be imported, and the wooden crates they arrive in could be re-used. Though these elements would be imported, they must still be of responsible integrity. For example, insulation could be wool batting made from sheep's wool normally discarded at Quebec farms. Pelts can be used suspended from the walls to provide an extra layer of insulation, akin to the inward facing furs added to traditional clothes to provide greater insulation. 
The use of materials in the construction that are naturally familiar to the Inuit would also engender the integration and understanding of contemporary building technique with that of traditional architecture.

A physical model was created that would allow members of the community to visualise a proposed architecture in a more tangible way. As many in the community are quite skilled with three dimensional creations in marble and serpentine, having an accessible scale model in the community was deemed essential to represent the idea. The roof removes to allow people to peer inside, and navigate the spaces with their fingers as well as their eyes. The model was made to fit the dimensions of regional jets carry-on cabins that fly into Nunavut $(25 \mathrm{~cm} \mathrm{x} 46 \mathrm{~cm} \times 55 \mathrm{~cm})$. However, should the connecting flight be on a turbo-prop, the model would have to be checked in at the counter. A sturdy plywood case was made for this situation. 

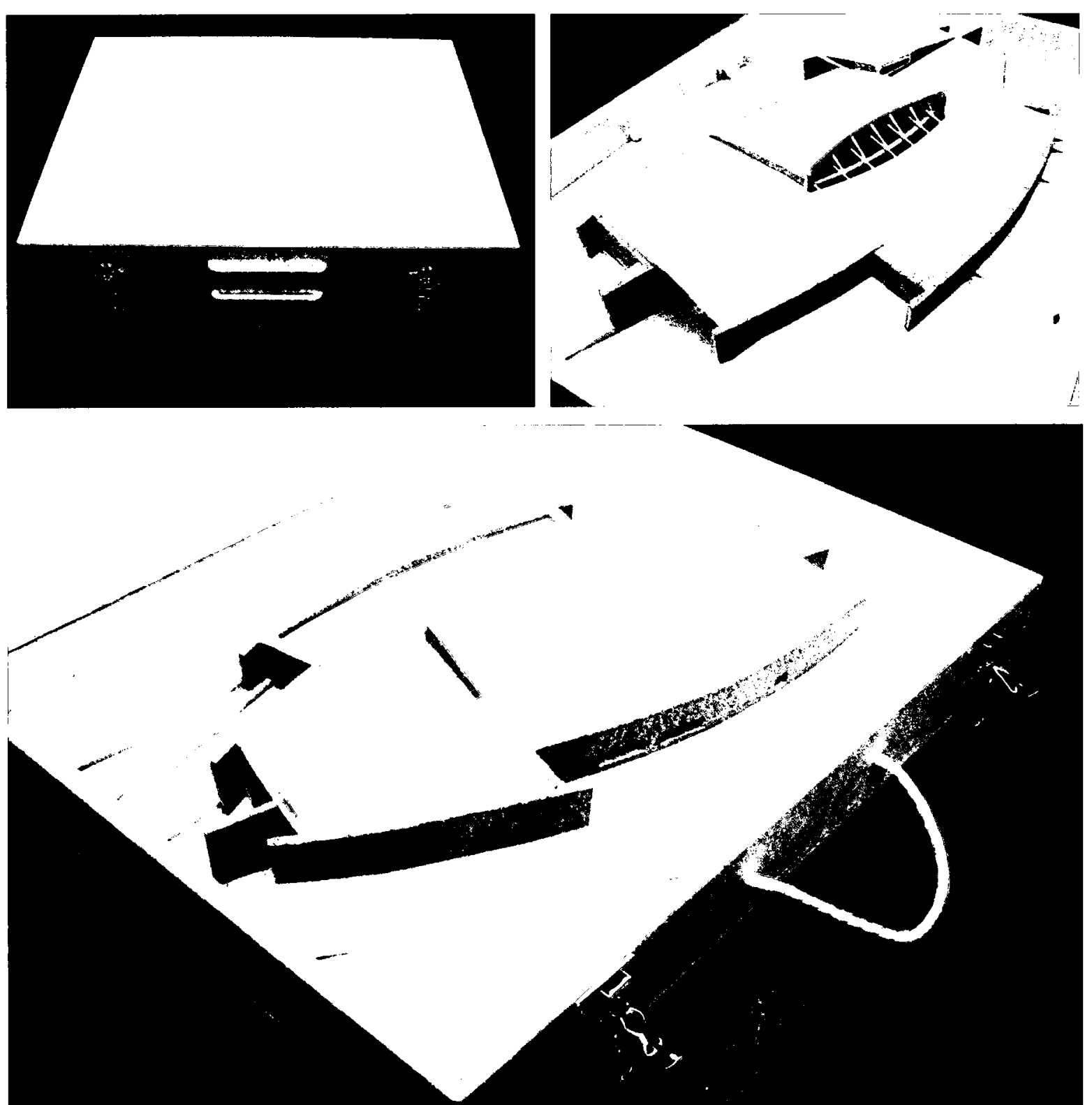

Fig. 39: Carry-on Model 
A preliminary virtual model has also been initiated and can be found on the wiki, should the physical model not survive the north.
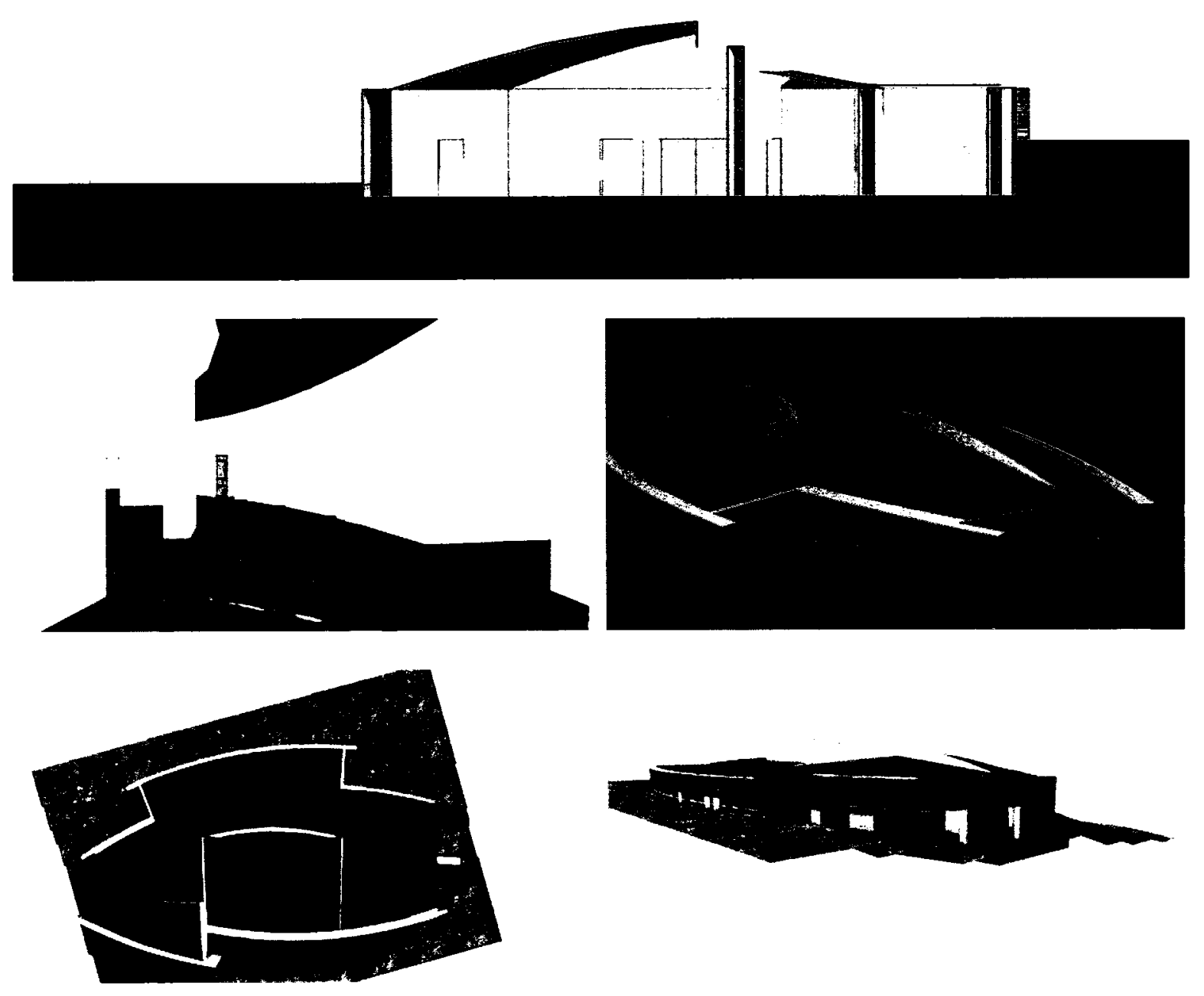

Fig. 40. Virtual Model 
Notes

${ }^{74}$ Hendry, Joy. Reclaiming Culture: Indigenous People and Self-representation (New York: Palgrave Macmillan, 2005) 215.

${ }^{75}$ In fact, Ilippallianginnarniq, the Inuit approach to intergenerational learning which, coupled with community development strategies, has resulted in literacy initiatives that strengthen links between youth and elders, capture oral history and promote bi-literacy for young children and their families: Kim Crockatt. Building Culture and Community: Family and Community Literacy Partnerships in Canada's North

${ }^{76}$ Krinsky, Carol Herselle. Contemporary Native American Architecture: Cultural Regeneration and Creativity. (New York: Oxford University Press, 1996) 207.

${ }^{77}$ Canadian Museums Association website. Museum definition http://25538.vws.magma.ca/en/info_resources/reports_guidelines/museum_definition/index.php

${ }^{78}$ The Cross Cultural Taskforce of the International Executive Council of Museums (Report of the Working Group on Cross Cultural Issues of the International Council of Museums (ICOM) Presented at the $89^{\text {th }}$ session of the Executive Council of ICOM on December 1997

http://icom.museum/diversity.html) has seven guiding principles that mirror the objectives laid out by the people of Cape Dorset:

1. CULTURAL DIVERSITY: Recognition and affirmation of cultural diversity at the local, regional and international levels and the reflection of this diversity in all policies and programs of museums across the world.

2. PARTICIPATORY DEMOCRACY: Promotion of heritage representation with active input from all stakeholders through appropriate processes of consultation, negotiation and participation.

3. COOPERATION AND COORDINATION: Cooperation and coordination to share projects and enhance cultural exchanges so as to maximise on resources and expertise at the regional and global levels. 4. PEACE AND COMMUNITY BUILDING: Promoting the sense of place and identity of diverse peoples through the appreciation of their diverse inheritances and the fostering of a shared vision inspired by the spirit of reconciliation.

5. INNOVATION AND INSPIRATION: Fostering of creativity and the development of challenging approaches to stimulate inclusive heritage consciousness in multicultural societies.

6. CAPACITY BUILDING: Directed and sustained endeavours to increase the operational capacity of museums to respond to transformation and changes in multicultural societies with vigour and insight.

7. RESOURCEFULNESS: Maximisation on the ways that will encourage the diversification of resources to address competing demands of cultural equity concerns and cultural economics.

${ }^{79}$ Report of the Working Group on Cross Cultural Issues of the International Council of Museums (ICOM) Presented at the $89^{\text {th }}$ session of the Executive Council of ICOM on December 1997 http://icom.museum/diversity.html 
${ }^{80}$ Papanek, Victor. The Green Imperative: Natural Design for the Real World. (New York: Thames and Hudson, 1995) 229.

${ }^{81}$ Edmund Carpenter, Frederick Varley and Robert Flaherty. Eskimo. (Toronto: University of Toronto Press. 1959) 16.

${ }^{82}$ Krinsky, 119. 


\section{Potential}

Given the participatory nature of this research it is of utmost advantage that the results benefit the community. The research itself will be left in the hands of the community to use as required. To accommodate different groups and varying degrees of interest it is best to provide variety of different ideas and activities that act as catalysts for community initiated programs and activities.

\section{Housing}

The principals used in the cultural healing centre can be applied as potential solutions to housing. The spatial qualities of openness and versatility are certainly appropriate in the home. The idea of the contemporary Arctic house in relationship to the community as a whole is also to be reconsidered. The Canadian Centre for Architecture held an architectural competition in 2009 on this exact issue, with focus on the community on Inukjuak, Nunavik, Quebec. ${ }^{83}$ The ideas raised here contributed to the ongoing dialogue of housing, the relationship between the house and the community, and issues of mobility, energy use, environmental responsibility.
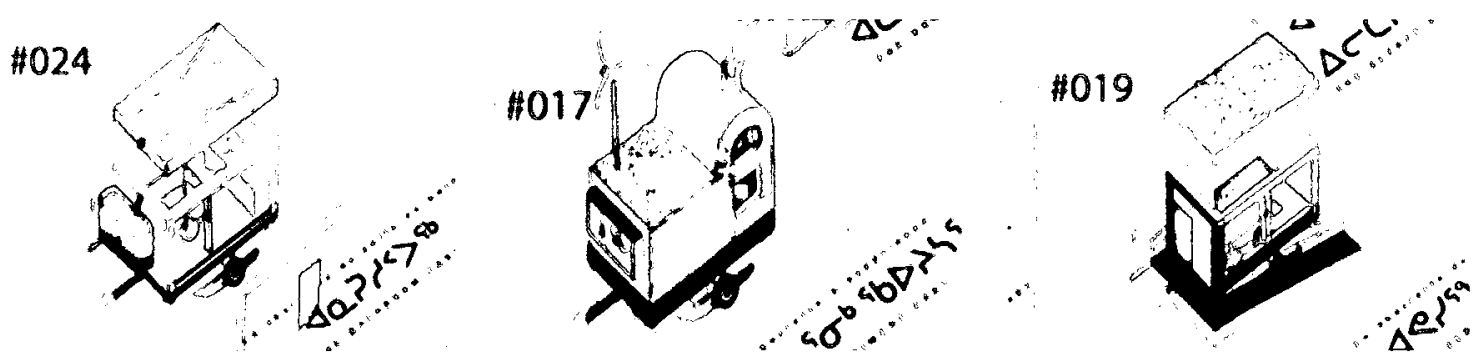

Fig. 41: Variations of a Cart from competition submission: A Cartographic Cartoon 


\section{Propagation and Awareness}

Parts of the continuum of this project are potentially a variety of initiatives for activities and other tools to engage people in the architectural exploratory dialogue and other cultural regenerative discourses. The youth that participated in the design workshops were of varying age groups; activities must be geared accordingly. Among the potential awareness activities are children's books, schoolyard activities, classroom projects and activities, day camps, games and websites for youth. For the wider community, a resource website would prove beneficial with various appropriate links as well as contacts for local government and development agencies. A wiki for this thesis has been prepared to allow anyone in the world with internet access to see visuals and discuss the project indefinitely: http://arcticarch.pbworks.com/. This allows people to sign up and continue contributing architectural designs for this project, or any other. Within a competed cultural healing centre, the resource and multi-media component would enable youth to access and continue adapting to new technologies and virtual resources with a rich cultural backdrop. These are some among many diverse potential awareness and promotional tools that may further the catalytic momentum of architectural research.

\section{Workshop Studio}

Several interested parties were involved throughout the discourse of this thesis that suggested that cross-cultural programs could be extended beyond Cape Dorset's geographic vicinity. 
Partnerships may be available between southern universities in Canada and Northern Europe, and between people from northern and southern realms in both regions. An architectural design studio organised and run by the universities may allow Inuit, Sami and potentially other indigenous northern peoples (or from any terrestrial region for that matter) to study architecture in their respective locales. It also provides an opportunity for group or individual exchanges of students within the northern realms, with potential to expand into the southern realms. It is also an opportunity that may be made available to young Northerners who may not be otherwise be able to attend a University in the south. This cross-cultural outreach would provide a basis for youth to develop networks and relationships with people of a variety of backgrounds and perspectives, and to learn more about themselves and others. It would further the ability of local communities to retain talent and expand the local knowledge base.

Further explorations may involve groups of students in each region working on the same architectural project long distance within virtual immersive environments, and shorter term visits to the other group members in the other regions. This would further the goal of selfsufficiency within regions with the added value of engagement with other regions. The use of human creativity as resource extends beyond that of the typical arts and cultural endeavours, but extends into all realms of human faculty: science and traditional knowledge, health, education, infrastructure, and so on. 
Interdisciplinary collaboration between architects, planners, government agencies, geographers, anthropologists, sociologists, and educators would further contribute to a progressive advance in all sectors of human development. Funding may be available through embassies, universities and government agencies in pursuit of such endeavours, and members within the universities and communities may take the opportunity to have architecture and community planning initiatives brought into fruition. Ultimately, the value given to active cultural development and celebration leads to the healing uplifting and resilience of people.

Notes

${ }^{83}$ Interuniversity Charrette: $14^{\text {th }}$ Edition. Housing Crisis in the North October $30^{\text {th }}-$ November $3^{\text {rd. }}$ <http://www.cca.qc.ca/charrette/index_en.html> Entry by author Morgan Ip and colleagues Maximilian Hugh, Richard Smith, Edward Solodukhin, and Nicolas Valenzuela garnered Honourable Mention in the Agitation Category for the submission: A Cartographic Cartoon. The project's aim was to use carts as small buildings that acted as characters who recount the diversity of the needs and activities of the people of Nunavik. 


\title{
Conclusion
}

\author{
"Architecture is a formal expression of a culture's collective identity, both in an historical \\ and contemporary sense. It defines people, cultures and nations, and plays an important \\ part in society's definition of itself and its identity, not only from a contemporary \\ perspective, but also in terms of their future development and what they want to \\ become." - Joar Nango ${ }^{1}$
}

Culture is a powerful healing tool, and its enrichment and transmission positively contributes to the health of a people and their community. The dynamic energy and character of a community may be manifested in architectural form, brimming with human creative potential and activity within. This is strengthened with each new idea and accomplishment that enriches the cultural milieu of the human race in the face of monolithic global forces. Cross-cultural collaboration does not diminish but rather enhances the participating cultures. Architecturally and otherwise, the importance of inclusively in the design process for such culturally relevant projects is exemplified by the strength of participation during this research in Cape Dorset. The outcome of these design workshops will remain within the community and there is further potential that the cultural healing centre may move beyond a design phase and become a living testament to the culture of Cape Dorset. As social networks get more and more complex, evolving beings will be able to manage the re-connection of body, mind and environment. The proposed cultural healing centre is an opportunity to seize this connection and allow the Inuit culture to evolve with and make important contributions to the global human culture by strengthening and 
reaffirming their own part of it. Constructive relationships with southern Canadians, other indigenous people around the world and other non-indigenous majority cultures will allow for collaborations that not only heal the local community but humankind as a whole. With the critical mass of human beings currently exhausting the biological world, it is essential that all peoples everywhere be lifted up economically and creatively in relationships that prevent conflict and engender harmony and balance. ${ }^{2}$ Enhanced responsiveness to environmental conditions may then follow.

More creative potential can be drawn from a shift towards sustainable and culturally relevant communities, and the people of Cape Dorset have already proved highly successful at integrating foreign artistic media into their culture with their prints and carvings. This capacity is further shown in their instigation and collaboration in designing a cultural healing centre. The potential exists to move beyond the general plan and design of a centre towards different scales, from construction and material details to whole community planning. This further extends in to realms of all human enterprise. For the Earth as a whole is a closed system with everything interconnected. The events that happen there are eventually felt around the world, and as people around the world are collectively engaging with each other like never before, there is a strong movement towards working with the changes. People who were once silenced are now looked upon to collaborate on global issues. The Arctic voice is ready to be heard. 
Notes

1 Joar Nango. "Sámi Architecture," Báiki Issue 30 Summer 2008: 14-15.

2 This notion of the creative class rising as a new human 'age' post industrial and postknowledge is detailed further by Prof. Richard Florida in his book, The Rise of the Creative Class. 


\section{Bibliography}

“Canadian Climate Normals 1971-2000.” Environment Canada. <http://climate.weatheroffice.ec.gc.ca/climate_normals/results_e.html?StnID=1738\&a utofwd $=1>$

Canadian Centre for Architecture. Interuniversity Charrette: $14^{\text {th }}$ Edition. Housing Crisis in the North October $30^{\text {th }}-$ November $3^{\text {rd. }}<$ http://www.cca.qc.ca/charrette/index_en.html $>$

Cardinal, Douglas and Jeanette Armstrong. The Native Creative Process. Penicton, BC: Theytus Books, 1991.

Carpenter, Edmund. "Image Making in Arctic Art." Sign, Image and Symbol, Ed. Gyorgy Kepes. New York: George Braziller, 1966

Carpenter, Edmund, Frederick Varley and Robert Flaherty. Eskimo. Toronto: University of Toronto Press. 1959

Chacon, Mark A. Architectural Stone: Fabrication, Installation, and Selection. New York: John Wiley \& Sons, 1999.

Connah, Roger. Grace and Architecture. Tampere, Finland: Rakennustieto Oy, 1998.

Crockatt, Kim and Suzanne Smythe. "Building Culture and Community: Family and Community Literacy Partnerships in Canada's North.” Nunavut Literary Council. 2009. <http://www.nunavutliteracy.ca/english/resource/reports/building/15.htm>

Dawson, Peter C. "Examining the Impact of Euro-Canadian Architecture on Inuit Families Living in Arctic Canada." 4th International Space Syntax Symposium. London, England, June 172003.

Dawson, Peter. "Unfriendly Architecture: Using Observations of Inuit Spatial Behaviour to Design Culturally Sustaining Housis in Arctic Canada." Housing Studies 23.1 (2008): 111.

de Cuéllar, Javier Pérez, et al. Our Creative Diversity: Report of the World Commission on Culture and Development. France: UNESCO Publishing / Oxford \& IBH Publishing Co, 1995. 
Dorais, Louis-Jaques. Quaqtuq : Modernity and Identity in an Inuit Community. Toronto: University of Toronto Press, 1997.

Florida, Richard. The Rise of the Creative Class: And How It's Transforming Work. Leisure, Community and Everyday Life. New York, 2002.

Gaski, Harald. "Introduction: Sami Culture in the New Era." Sami Culture in a New Era: The Norwegian Sami Experience. Ed. Harald Gaski. Seattle: University of Washington Press, 1997.

Graburn, Nelson H.H. Eskimos Without Igloos: Social and Economic Development in Sugluk. Boston: Little, Brown and Company, 1969.

Hendry , Joy. Reclaiming Culture: Indigenous People and Self-Representation. New York: Palgrave Macmillan, 2005.

Inclusion by Design: Equality, Design and the Built Environment. Commission for Architecture and the Built Environment (CABE) London. November 27, 2008.

Jetsonen, Sirkkaliisa. Sacral Space: Modern Finnish Churches. Tempere: Rakennustieto Oy, 2003.

Krinsky, Carol Herselle. Contemporary Native American Architecture: Cultural Regeneration and Creativity. New York: Oxford University Press, 1996.

Kvernmo, Siy. "Developing the Sami Health Services - A Medical and Cultural Challenge." Sami Culture in a New Era: The Norwegian Sami Experience. Ed. Harald Gaski. Seattle: University of Washington Press, 1997.

Lampugnani, Vittorio Magnago. “Technology, Industrialisation, Materiality, Simplicity: Thoughs on a Reflective Modernity." Material Stone: Constructions and Technologies for Contemporary Architecture. Ed. Christoph Mäckler. Basel: Birkhäuser / Publishers for Architecture, 2004.

Lee, Molly and Gregory A. Reinhardt. Eskimo Architecture: Dwelling and Structure in the Early Historic Period. Fairbanks: University of Alaska Press, 2003.

Magnago Lampugnani, Vittorio. "Technology, Industrialisation, Materiality, Simplicity: Thoughts on a Reflective Modernity." Material Stone: Constructions and Technologies for Contemporary Architecture. Ed. Christoph Mäckler. Basel: Birkhauser-Publishers for Architecture, 2004. 
Mehtälä, Maila. "Rectification to the Design History of the Temppeliaukio Church." <http://www.temppeliaukio.fi/>.

Massey, Doreen. Space, Place, and Gender. Minneapolis: University of Minnesota Press, 1994.

"Museum Definition." Canadian Museums Association. 2008.

<http://25538.vws.magma.ca/en/info_resources/reports guidelines/museum definitio $\underline{\text { n/index.php }}>$.

Nango, Joar. “Sámi Architecture,” Báiki Summer 30 (2008): 14-15.

Papanek, Victor. The Green Imperative: Natural Design for the Real World. New York: Thames and Hudson, 1995.

"Population and Dwelling Counts, for Canada, Provinces and Territories, and Cencus Subdivisions (Municipalities), 2006 and 2001 censuses - 100\% data." Statistics Canada. <http://www12.statcan.ca/census-recensement/2006/dp-pd/hlt/97$550 /$ Index.cfm ?TPL $=\mathrm{P} 1 \mathrm{C} \& \mathrm{Page}=\mathrm{RETR} \& \mathrm{LANG}=\mathrm{Eng} \& \mathrm{~T}=302 \& \mathrm{PR}=62 \& \mathrm{~S}=1 \& \mathrm{O}=\mathrm{A} \& \mathrm{R}$ $\mathrm{PP}=25>$

Post, Jan W., Hubertus V. M. Hamelers, and Cees J. N. Buisman. "Energy Recovery from Controlled Mixing Salt and Fresh Water with Reverse Electrodialysis System." Environmental Science and Technology 42.15 (2008): 5785-5790.

"Qulliq Energy Corporation: Powering Nuavummiut Into the Future...Today: About Us." Qulliq Energy Corporation. <http://www.nunavutpower.com/home/index.php?option=com_content\&task=view\&i $\underline{\mathrm{d}=17 \& \text { Itemid }=32>}$.

Rapoport, Amos. Housing Form and Culture. Englewood Cliffs, NJ: Prentice-Hall Inc., 1969.

\section{Report of the Working Group on Cross Cultural Issues of the International Council of} Museums (ICOM): Presented at the 89th session of the Executive Council of ICOM on Presented at the 89th session of the Executive Council of ICOM on December 1997. International Council of Museums <http://icom.museum/diversity.html $>$.

Rochon, Lisa. Up North: Where Canada's Architecture Meets the Land. Toronto: Key Porter Books Limited, 2005.

Semple, Bill. "Tradition and Technology: The Designing of Housing for the Arctic." Exploring Domestic Spaces in the Circumpolar North. Tromsø, Norway. October $2^{\text {nd }}, 2008$. 
The Government of Nunavut (Nunavut Housing Corporation) and Nunavut Tunngavik Inc. "Housing in Nunavut Overview." Nunavut Housing Corporation. <http://www.nunavuthousing.ca/i18n/english/h_overview.html>

The Government of Nunavut (Nunavut Housing Corporation). "Nunavut Ten-Year Inuit Housing Action Plan." Nunavut Housing Corporation. <http://www.nunavuthousing.ca/i18n/english/pdf/10YearHousing\%20Plan_Eng.pdf> The Government of Nunavut (Nunavut Housing Corporation). "Public Housing." Nunavut Housing Corporation. <http://www.nunavuthousing.ca/i18n/english/p_public.html >

"Tides, Currents, and Water Levels." Fisheries and Oceans Canada. < http://www.waterlevels.gc.ca/english/Canada.shtml >.

Zrudlo, Leo. “The Design of Climate Adapted Arctic Settlements." Cities Designed for Winter. Ed. Jorma Mänty and Norman Pressman. Helsinki: Building Book Ltd, 1988. 
Appendix A: Participant Consent Agreement for Project Entitled:

\section{An Appropriate Arctic Architecture: A Centre for Healing}

Morgan Ip, M.Arch. candidate, School of Architecture, Carleton University, Ottawa, Ontario. Tel.: . Email: mtang@connect.carleton.ca

\section{Introduction}

The purpose of this informed consent agreement is to inform you about this project and to ensure your rights.

\section{Project Summary}

The purpose of this study is to rethink the way that buildings are built in the Canadian Arctic. Whether it is a house or a community building of some kind, the spaces people use should reflect their culture and their environment. As the climate and society itself changes the built environment should respond to these changes and adapt accordingly.

To better understand how to build the most appropriate buildings in the North, an understanding of the problems and advantages of current building is needed, and this can only be done by working with the people that live, learn, work and play in them.

The particular building chosen to design is a Centre for Healing. The notions of healing are important in this study, and can refer to the healing of the body, spirit or essence, environment, relationships, or society. The metaphor of healing can be translated into the building and offers a strong starting point for design that is intended to reconnect with culture and place.

The resultant Master of Architecture thesis will be presented back to the community for further discussion. The building may or may not proceed beyond theoretical stages, but the ensuing discussion will benefit the community and may lead to fresh building ideas within.

\section{Informed Consent Agreement}

I would like to invite you to participate in the project if you are interested. Your participation in this project is completely voluntary. It is estimated that the study will take roughly 4-6 hours at the Visitor Centre, or at a location that is convenient to you, and may take place as one session of divided into smaller sessions.

The design charrette will commence with a description of the project, and a discussion on what a healing centre is, and how it may start to be designed. The design portion will follow in which the participants will design, collectively, what they think a healing centre should be. There will be an information portion after the charrette in which I will present the work and designs that I have already done. This is so that your ideas are not influenced by my previous work. Feedback and a discussion of what $I$ have considered to date on the healing centre would immediately follow. A feedback and discussion session would then ensue. The workshop would then come to a close.

The charrette will be conducted in English and Inuktitut, in the presence of an interpreter. There is no foreseen risk to you in participating in this study. You do not have to answer any questions which make you uncomfortable. Should you choose to stop or withdraw from the study you may do so. You may decide at that time if I may use any of the information you have provided or you may request that it be destroyed. 
I may document the design charrette by taking photographs. I will ask permission to take photographs of you. Should you decline I will not take a photo. If you accept I will ask you to sign a Photo Release form and I would guarantee it would be used only for research purposes relating to this project, its related publications and presentations. You will be cited in any photographs with your image.

This research will be conducted with your best interests in mind. You will be acknowledged in any report, presentation or final written thesis in which your ideas or drawings are used or noted.

Refreshments will be served, and a small gift as a token of my appreciation will be given to all participants

If you have any concerns please do not hesitate to contact me at or morgan.iptang@gmail.com. If you have further concerns you may contact:

Dr. N.C. Doubleday, Associate Professor,

Prof. Antonio Gualtieri, Chair

Associate Chair of the Department of Geography Carleton University Research Ethics Committee and Environmental Studies,

Carleton University

Carleton University

1125 Colonel By Drive

1125 Colonel By Drive

Ottawa, Ontario K1S SB6

Ottawa, Ontario K1S SB6

Tel: 613-520-2517

Tel: 613-520-2600 extension: 8370

E-mail: ethics@carleton.ca

E-mail: Nancy_Doubleday@carleton.ca

\section{Informed Consent}

By signing below, you are acknowledging that you have been informed about this study and agree to participate.

I, name here) wish to participate in this study. (please print your

I will be given credit and cited for any work, drawings or ideas that are used in the resultant project.

Participant Signature

Date

Researcher Signature

Date

Witness Signature

Date 
Appendix B: Participant Consent Agreement for Minors for Project Entitled:

\section{An Appropriate Arctic Architecture: A Centre for Healing}

Morgan Ip, M.Arch. candidate, School of Architecture, Carleton University, Ottawa, Ontario. Tel.:

mail: mtang@connect.carleton.ca

The purpose of this informed consent agreement is to inform you about this project and to ensure your (or your children's) rights.

\section{What is the project?}

The purpose of this study is to rethink the way that buildings are built in the Canadian Arctic. Whether it is a house or a community building of some kind, the spaces people use should reflect their culture and their environment. As the climate and society itself changes the built environment should respond to these changes and adapt accordingly.

To better understand how to build the most appropriate buildings in the North, an understanding of the problems and advantages of current building is needed, and this can only be done by working with the people that live, learn, work and play in them.

The particular building chosen to design is a Centre for Healing. The notions of healing are important in this study, and can refer to the healing of the body, spirit or essence, environment, relationships, or society. The metaphor of healing can be translated into the building and offers a strong starting point for design that is intended to reconnect with culture and place.

The resultant Master of Architecture thesis will be presented back to the community for further discussion. The building may or may not proceed beyond theoretical stages, but the ensuing discussion will benefit the community and may lead to fresh building ideas within.

\section{What will the participants do?}

People in the community, including young people and children, are invited to participate in a design charrette, which is a meeting in which we will talk about and design a building together. Participants will be given various pencils, crayons, and other materials and paper to draw a healing place. The materials will be left in the community as appreciation for the community's contribution.

The results of this project will be published in a thesis and made available to the community. It is to give an idea of what the people of Cape Dorset desire in buildings, especially a healing centre. The project is optional and not part of the participant's regular classes, activities or treatments.

Refreshments will be served. 
If you have any concerns please do not hesitate to contact me at .

or morgan.iptang@gmail.com. If you have further concerns you may contact:

Dr. N.C. Doubleday, Associate Professor and Associate Chair of the Department of Geography and Environmental Studies,

Carleton University

1125 Colonel By Drive

Ottawa, Ontario K1S 5B6

Tel: 613-520-2600 extension: 8370

E-mail: Nancy_Doubleday@carleton.ca

Or

Prof. Antonio Gualtieri, Chair

Carleton University Research Ethics Committee

Carleton University

1125 Colonel By Drive

Ottawa, Ontario K1S 5B6

Tel: 613-520-2517

E-mail: ethics@carleton.ca

I, , have read the above letter and understand that my child is participating in a research project and I voluntarily consent for him/her to participate.

I permit his/her contributions to be recognised in text in any reports or publications.

Signature

Printed Name
Witness

Printed Name

Date 


\section{An Appropriate Arctic Architecture: A Centre for Healing}

Morgan Ip, M.Arch. candidate, School of Architecture, Carleton University, Ottawa, Ontario. Tel.:

mail: mtang@connect.carleton.ca

These questions will be asked in the beginning stage to get participants thinking about how they would design.

\section{Topic One: Healing Centre Meaning}

What should a healing centre do or what is it for?

What does healing mean to you?

How should this centre address healing?

Who uses it?

Does the meaning or use ever change?

\section{Topic Two: Site Considerations and Building Materials}

Where would you think a healing centre should go? Why?

How does the building relate to its surroundings and the environment as a whole?

Does the building relate to beings other than people? How?

Does climate change affect the building? If so, how does this affect where it goes and what it is? What should it be made out of? Why?

Can it be made with local materials? If so, how will the materials be collected to make the building?

Who should build it?

How do materials reflect the intention or character of the building?

Can this building actually be built? If not, why?

If so, can it be done by local people?

\section{Topic Three: The Building Design}

What do you think the healing centre should look like?

What sort of spaces are inside?

What sort of spaces are outside?

What spaces are both inside and outside?

How much space should be used?

How will it be used?

How long should it last?

What activities take place in and around the centre?

How does the space reflect the activities?

Should traditional spaces be imitated, re-interpreted or neither? If so, how? If not, why?

Can it be used as a model for living for everybody? What parts of its design would you like to see in your home? 
Appendix D: Photo Release Form for Project Entitled:

\section{An Appropriate Arctic Architecture: A Centre for Healing}

Morgan Ip, M.Arch. candidate, School of Architecture, Carleton University, Ottawa, Ontario. Tel.: I .Email:mtang@connect.carleton.ca

I, __ hereby give the researcher my permission to take and use any photographs made of me, and which may be included in the final published thesis. If my picture is chosen for presentation or publication I give permission to be cited.

I declare that $\mathrm{I}$ am of the age eighteen years.

Signature

Printed Name
Witness

Printed Name 